\title{
Temperature and Production Efficiency Growth: Empirical Evidence
}

\author{
Surender Kumar \\ Email: skumar@econdse.org \\ Department of Economics \\ Delhi School of Economics
}

\author{
Madhu Khanna \\ Email: khanna1@illinois.edu \\ Department of Agricultural and \\ Consumer Economics \\ University of Illinois, Urbana-Champaign \\ 1301, W. Gregory Drive, Urbana, IL 61801
}

\section{Working Paper No. 298}

http://www.cdedse.org/pdf/work298.pdf 


\title{
Temperature and Production Efficiency Growth: Empirical Evidence
}

\author{
Surender Kumar ${ }^{1}$ and Madhu Khanna ${ }^{2}$ \\ ${ }^{1}$ Department of Economics, Delhi School of Economics \\ University of Delhi, Delhi 110007, INDIA \\ E-mail: skumar@econdse.org \\ $\&$ \\ ${ }^{2}$ Department of Agricultural and Consumer Economics \\ University of Illinois, Urbana-Champaign \\ 1301, W. Gregory Drive, Urbana, IL 61801 \\ E-mail: khanna1@illinois.edu
}

\begin{abstract}
This paper examines the marginal effects of temperature on the growth rate and variability in growth rate of Total Factor Productivity (TFP) of a country, as measured by its production efficiency relative to a stochastic frontier. Using panel data for 168 countries for the period 1950-2014 to estimate a one-step stochastic frontier function, we find that temperature has a concave relationship with the growth rate of production efficiency and with the variability in this growth rate. We observe that hotter than the average temperature is not only detrimental to production efficiency growth but also makes the growth less stable than otherwise and these effects are larger in very hot countries with average annual temperature greater than $25{ }^{\circ} \mathrm{C}$. More importantly, we observe that the detrimental marginal effects of higher temperature depend on the level of economic development of a country; they are larger for poor countries relative to rich countries. Our findings have implications for the specification of climate damage functions in integrated assessment models and estimates of country-specific social cost of carbon.
\end{abstract}

Key Words: Temperature, Production efficiency growth, Stochastic frontier analysis (SFA), Non-linear effects

JEL Classification: E23, O13, Q54, Q56

Acknowledgements: We are very thankful to Saumya Verma for helping us in drawing the figures. Madhu Khanna gratefully acknowledges support from NIFA, USDA for this research. 


\section{Introduction}

Growing concerns about the impacts of climate change have led to a large literature examining micro-economic and macro-economic effects of rising temperature. This literature has focused on the effects of temperature on agricultural sector (e.g., Mendelsohn et al., 1994; Deschenes and Greenstone, 2007), on labor productivity (e.g., Graff-Zivin and Neidell, 2014) and on other dimensions of economic activities such as mortality and morbidity (e.g., Barreca, 2012; Miljkovic et al., 2018), energy consumption (e.g., Forrest, 2018; PérezLombard et al., 2008; Mansur et al., 2008), manufacturing and trade (e.g., Yunfeng and Laike, 2010; Wenz and Levermann, 2016; Willner et al., 2018), and conflict (e.g., Hsiang et al., 2013). ${ }^{1}$ Focusing only on a single sector or single factor of production can provide biased estimates of the effect of temperature increase on economic activities (Zhang et al., 2018).

Other studies have examined the relationship between temperature and macro-economic indicators of economic activity using reduced form statistical methods (e.g., Dell et al., 2012; Heal and Park, 2013; Burke et al., (BHM) 2015; Pretis et al., 2018). Dell et al. (2012) observe linear effects of increases in temperature on economic growth in developing countries only. However, Pretis et al. (2018), Burke et al (2015) and Heal and Park (2013) find that hotter than average years are associated with a decline in per capita income in hot climatic zones but higher per capita income in cold regions, irrespective of the level of development in a country.

A relatively overlooked impact of climate change is on growth in total factor productivity (TFP). TFP is defined as a ratio of aggregate output to aggregate input (Syverson, 2011, p.329). It is preferable to partial productivity measures, such as labor productivity, as it incorporates all outputs and inputs in a single measure (Ortiz-Bobea et al., 2018). TFP can also be interpreted as a measure of the efficiency of a productive process since it shows how productively physical inputs are being utilized. Growth rate of TFP accounts for an economy's ability to increase output without a corresponding increase in the physical input base. It differs across countries and it is an important determinant of economic growth in a country. Since production is uncertain, TFP growth rates can also vary around an average value.

Climate change can affect the growth rate of TFP and variability in this growth rate in various ways: by reducing ecosystem services critical for economic growth, leading to diversion of resources away from research and development (R\&D) activities towards climate change mitigation and adaptation and reconstruction of capital as well as by reducing the productivity of factors such as agricultural land and labor (Moyer et al., 2014). In estimating the social cost of carbon, some integrated assessment models (IAMs) such as the Dynamic Integrated Climate-Economy (DICE) model assume that TFP is determined exogenously and climate change reduces aggregate output directly (Tisgaris and Wood, 2016). Several scholars have modified this assumption in IAMs and allowed for the possibility that climate change may reduce TFP growth and thereby alter long term growth instead of affecting output directly. These studies show that the social cost of carbon is very sensitive to the effects of climate change on productivity (Moore and Diaz, 2015; Dietz and Stern, 2015; Moyer et al., 2014). For example, Dietz and Stern (2015) show that consumption per capita will reduce by 11.4 - 15 times in 2205 relative to 2005 if annual global TFP growth

${ }^{1}$ For comprehensive review on the impact of climate change on various economic activities, see Dell et al. (2014) and Carleton and Hsiang (2016) 
declines by about 0.20 percentage points. These studies assume that the effect of climate change on TFP is the same across countries which is unlikely to be a correct assumption. A key contribution of this study is to examine the variations in the effect of climate change on TFP across countries, due to differences in the climatic zone in which a country is located and its level of economic development; these can influence the country's capacity for mitigation and adaptation and thus the effects of climate change on productivity. An accurate assessment of the effect of climate variables on TFP and its variation across countries is critical to obtain a valid estimate of the global social cost of carbon.

However, there is relatively limited empirical evidence of the effect of climate change on TFP and how this effect differs across countries. A few studies have estimated the effect for a single country or for a small subset of countries. For example, Ortiz-Bobea et al. (2018) examine the effect of climate variables on agricultural TFP in the US. Zhang et al. (2018) estimate the effect of temperature on TFP of Chinese manufacturing firms. Letta and Tol (2018) examine the relationship between TFP growth and change in temperature shocks using a panel dataset of 60 countries over the period of 1960 to 2006. While Ortiz-Bobea et al. (2018) measure agricultural TFP as a ratio of aggregate agricultural output to aggregate agricultural input, the other two studies measure TFP by Solow residual. These studies have used a two-step approach that involves measuring TFP in the first stage followed by regressing TFP on temperature in the second stage. Moreover, these studies do not consider the effect of temperature on variability in TFP growth. Some studies find that increases in climate variability generally decreases mean crop yields, and increases crop yield variance (e.g., Urban et al., 2012). A two-step approach has been known to lead to biased estimates if the model estimated at the first step for estimating TFP is mis-specified (Wang and Schmidt, 2002). The mis-specification could arise due to correlation between factor inputs and determinants of TFP and lead to biased estimates of the impact of climate change on production efficiency.

In this study we measure TFP of a country by its productive efficiency in converting physical inputs into GDP. Productive efficiency is determined relative to a stochastic frontier and we examine the extent to which climate variables affect a country's ability to grow its productive efficiency or TFP. We use the terms production efficiency growth and TFP growth synonymously and interchangeably throughout the paper. A key contribution of this paper is to analyze the effects of temperature on growth and stability of production efficiency using a one-step stochastic frontier production function approach. We specifically seek to examine whether level of economic development of a country mitigates the effects of climate factors on growth and variability of productive efficiency and the extent of non-linearity in these effects.

Earlier studies have modeled the non-linearity of temperature impacts on economic activities by either adding its quadratic term as an explanatory variable (e.g., Burke et al., 2015) or arbitrarily discretizing the annual distribution of daily temperature in a fixed set of temperature bins (e.g., Zhang et al., 2018). ${ }^{2}$ In the present study, we flexibly parameterize both the mean and variance of the one-sided error term (efficiency growth) and the manner in which it is influenced by temperature and precipitation in the stochastic frontier of output growth; within this framework nonlinearity arises as a result rather than an assumption. The

\footnotetext{
${ }^{2}$ By a non-linear effect, we mean that temperature can have both positive and negative effects on efficiency growth and its variability, within a sample depending on the values of temperature.
} 
mean measures the expected level of growth in production efficiency; whereas variance measures uncertainty in growth of production efficiency (Bera and Sharma, 1999).

We use a panel dataset for 168 countries that differ in their level of economic development and temperature zones in which they are located. The data covers the period 1950-2014.We find that annual temperature variations have non-trivial effects on the expected mean of production efficiency growth, but the direction and magnitude of these effects are related to the location of a country relative to the optimal climate zone. We find that the optimal temperature zone lies somewhere between 12 to 15 degree Celsius $\left({ }^{\circ} \mathrm{C}\right)$. This finding corroborates with Burke et al. (2015). ${ }^{3}$ That is, non-linear marginal effects of temperature increase on production efficiency growth at the macro level are consistent with the temperature-performance relationship observed at the micro levels. ${ }^{4}$

We also find that inter-annual variability in temperature affects both, expected mean and variance of production efficiency growth. In countries located in cold regions (average annual temperature less than $15^{\circ} \mathrm{C}$ ) an increase in temperature not only increases efficiency growth but makes it more stable than before or the marginal effects are negligible, but in hot countries (average annual temperature greater than $20^{\circ} \mathrm{C}$ ) further increase in temperature not only decreases efficiency growth but also renders it less stable than otherwise. This finding reflects the importance of climate driven changes in the 'fatness' of production efficiency distribution tails. ${ }^{5}$ The results provide empirical foundation for the parameters of the damage function in the IAMs for assessing possible responses of climate policies.

The results also reveal that higher levels of income moderate the marginal impact of temperature increase on both the mean and variance of efficiency growth; the impacts are more detrimental in poor countries in comparison to rich countries even though they are located in the same temperature zone. However, countries that are located in very hot climate zone (average annual temperature greater than $25{ }^{\circ} \mathrm{C}$ ) observe high marginal impacts irrespective of the level of per capita income.

The rest of the paper is organized as follows: Section 2 outlines the conceptual background. Section 3 presents the data and descriptive statistics. The empirical strategy is described in Section 4 and the results are presented in Section 5. Section 6 sums up and concludes the paper.

\section{Conceptual Background}

We specify a stochastic production frontier with maximal output as a function of factor inputs and a random (normal) error. Actual output, therefore, equals maximal output minus a onesided error term, which represents a measure of production inefficiency. Econometric

\footnotetext{
${ }^{3}$ Burke et al (2015) find that productivity peaks at $13^{\circ}$ Celsius and declines at higher temperatures. Therefore, the fall-off in productivity concerning hotter and colder limits implies an optimal temperature zone for economic activities.

${ }^{4}$ In the microeconomic literature a single peaked relationship between productivity and temperature has been observed (e.g, Graff-Zivin and Neidell, 2014; Schlenker and Roberts, 2009).

${ }^{5}$ Our application captures climate-driven changes in the 'fatness' of efficiency growth distribution tails, the importance of which was stressed in Nordhaus (2011), Pindyck (2011), and Weitzman (2011).
} 
methods for estimation of stochastic production frontier are well developed in the literature. ${ }^{6}$ We incorporate the impact of temperature on efficiency growth in a standard Solow growth model with a Cobb-Douglas production function

$Y_{i t}=A_{i t} K_{i t}^{\alpha} L_{i t}^{\beta} ; \quad 0<A_{i t} \leq 1$

where $Y$ is aggregate output, $A$ is Hicks-neutral TFP, $K$ and $L$ are capital and labor inputs, respectively, $\alpha$ and $\beta$ are output elasticities of capital and labor, respectively and subscripts $i$ and $t$ stand for country and year, respectively.

To estimate the effect of temperature change on production efficiency, we specify a stochastic production frontier as follows. Equation (2) shows that output can deviate from maximum possible level due to random shocks $\left(v_{i t}\right)$ and/or because of production efficiency differentials, $\left[u_{i t}=\ln \left(A_{i t}\right)\right]$.

$\ln \ln \left(Y_{i t}\right)=\alpha \ln \left(K_{i t}\right)+\beta \ln \left(L_{i t}\right)+v_{i t}-u_{i t}$

$v_{i t} \sim N\left(0, \sigma_{v}^{2}\right)$

$u_{i t} \sim N^{+}\left(\mu_{i t}, \sigma_{u}^{2}\right)$

where random terms $v_{i t}$ and $u_{i t}$ are assumed to be independently and identically normally $(N)$ distributed with mean 0 and variance $\sigma_{v}^{2}$ and truncated normally $\left(\mathrm{N}^{+}\right)$distributed with mean $\mu_{i t}$ and variance $\sigma_{u}^{2}$; and $v_{i t}$ and $u_{i t}$ are distributed independently of each other, and of the regressors.

By converting equation (2) into first differences, we can express growth in output as follows:

$\ln \left(Y_{i t}\right)-\ln \left(Y_{i t-1}\right)=\alpha\left[\ln \left(K_{i t}\right)-\ln \left(K_{i t-1}\right)\right]+\beta\left[\ln \left(L_{i t}\right)-\ln \left(L_{i t-1}\right)\right]+\left[v_{i t}-v_{i t-1}\right]-\left[u_{i t}-u_{i t-1}\right]$

or

$\Delta \ln \left(Y_{i t}\right)=\alpha \Delta \ln \left(K_{i t}\right)+\beta \Delta \ln \left(L_{i t}\right)+\Delta v_{i t}-\Delta u_{i t}$

$\Delta v_{i t} \sim N\left(0, \sigma_{\Delta v}^{2}\right)$

$\Delta u_{i t} \sim N^{+}\left(\Delta \mu_{i t}, \sigma_{\Delta u_{i t}}^{2}\right)$

where $\Delta \ln \left(Y_{i t}\right)$ is growth in output, $\Delta \ln \left(K_{i t}\right)$ and $\Delta \ln \left(L_{i t}\right)$ are growth in capital and labor inputs respectively, and $\Delta u_{i t}$ is production inefficiency change. Estimates of production efficiency change are obtained as $\exp \left(-\Delta u_{i t}\right)$.

One way to account for the effects of climatic factors on production efficiency is to first obtain estimates of production efficiency change without accounting for these exogenous factors and then regress the estimates on a set of climatic factors. Wang and Schmidt (2002) demonstrate that estimates obtained using this 'two-step' approach are severely biased, and make a case for including all exogenous variables in the first step itself as determinants of production inefficiency. Therefore, we use a 'one-step' approach for estimating the stochastic production frontier. More specifically, mean and variation of change in the one-sided error term are parameterised as:

\footnotetext{
${ }^{6}$ A number of seminal papers starting with Aigner et al. (1977) and Meeusen and van den Broeck (1977) have contributed in this area.
} 
$\Delta \mu_{i t}=\delta_{0}+z_{i t} \delta$

$\sigma_{\Delta u_{i t}}^{2}=\exp \exp \left(\gamma_{0}+z_{i t} \gamma\right)$

where $\delta_{0}$ and $\gamma_{0}$ are intercept terms and $z_{i t}$ is a vector of exogenous climatic factors such as temperature and precipitation. We note that both mean and variance of inefficiency are parameterized by the same variables but allowed to differ in intercept and slope. Thus, though the climatic variables affect both the mean and variance of production inefficiency, the effects are not necessarily the same and could even have opposite signs.

We estimate equations (3) to (5) using a one-step using maximum likelihood estimator. This 'one-step' approach avoids the problem of the functional form affecting the determinants of production efficiency. Marginal effects of climatic factors on production inefficiency are obtained by taking expectations conditional on production inputs and climatic factors and then differentiating with respect to climatic variables (as in Wang 2002, 2003). ${ }^{7}$ By parameterizing both the mean and variance of one-sided error term we accommodate nonlinear production efficiency effect of exogenous variables such as temperature. If only the mean of inefficiency term is parameterized then $\gamma[k]=0$, implying monotonic effects of climatic variables on production efficiency and production uncertainty. Parameterization of both the mean and variance of inefficiency term implies that marginal effects depend on both $\delta[k]$ and $\gamma[k]$ which may differ both in sign and magnitude and lead to non-monotonic marginal effects. Marginal effects help in understanding the direction and magnitude of the impact of climate variables on production efficiency growth. If the sign of marginal effects of temperature is positive, it shows that an increase in temperature lowers production efficiency growth and enhances its variability. Since output is expressed in logarithmic terms, the marginal effects are interpreted as percentage change in growth of output or production inefficiency as a result of a one unit change in a climatic variable.

\section{Data}

We estimate the effects of temperature on production efficiency growth using information on output, inputs and climatic factors - temperature and precipitation at the country level. Data for this study is obtained from three sources. Information on GDP, labour and capital has been taken from Penn World Tables (PWT.9). Data on climatic variables is based on Burke et al. (2015) and the World Bank. ${ }^{8}$ Temperature is measured in ${ }^{\circ} \mathrm{C}$ and total precipitation is given in millimetres (mm) per year. ${ }^{9}$ The Burke et al (2015) and World Bank data differ in the method used to generate climate data at the country level and the time period covered. Climate data, which is available at a sub-country resolution is converted to a country-specific average by Burke et al (BHM) by constructing a population-weighted average. This data is available for the period 1960-2010. A population-weighted average provide an economically relevant climate realization (Heal and Park, 2013). On the other hand, the World Bank (WB) constructs an area-weighted average of climatic variables using information on temperature and precipitation of land areas obtained from the Climatic Research Unit (CRU) of the University of East Anglia (UEA). ${ }^{10}$ This data is available till 2017; however due to lack of availability of recent data on other variables such as capital stock and labor we are

\footnotetext{
${ }^{7}$ Formulas of estimating the marginal effects are given in Appendix.

${ }^{8} \mathrm{http}$ ///sdwebx.worldbank.org/climateportal/index.cfm?page=country_historical_climate

${ }^{9}$ For details on data for climatic factors, please see, Burke et al. (2015).

${ }^{10}$ For details on the climatic variable dataset provided by the UEA, please refer to Harrris et al. (2014)
} 
constrained to analyzing data for the 1950-2014 time period. Area weighted weather variables are appropriate from a meteorological perspective while population-weighted variables are likely to reflect the impact of climate on economic activities (Tol, 2017). ${ }^{11}$ Note that the sample correlation between temperature variables provided by these two sources is 0.96 and it is 0.90 between the two measures of precipitation.

We consider countries for which complete panel data on climatic and economic variables is available for at least 17 years. This leaves us with an unbalanced panel data for 153 countries over the period of 1960 to 2010 when the climatic variables are obtained from Burke et al. (2015) and for 168 countries when we use climatic data from the World Bank for the time period 1950 - 2014. In the first set we have a total of 6167 observations with 73 poor countries; and in the second set we have 77 poor countries and the total number of observations are $7952 .{ }^{12}$ We define a country to be poor if its per capita income, adjusted for purchasing-power-parity (PPP), was below the sample median in 1980, which was 2011US\$ $5173 .{ }^{13}$

Table A1 provides descriptive statistics of variables used in the study. It can be observed that poor countries are mainly located in hot temperate zones with an average temperature of about $22.5{ }^{\circ} \mathrm{C}$ whereas rich countries are on average experiencing a mean temperature of about $15.5^{\circ} \mathrm{C}$. Annual total precipitation does not differ much between the two groups of countries. There is considerable variability within each group of countries with respect to both economic and climatic factors. Table A1 shows that the difference in average temperature over time is higher in case of rich countries relative to poor countries.

\section{Empirical Estimation}

We estimate the production relationship defined through equations (3) to (5) with production inefficiency change and its variance as functions of average annual temperature and total annual precipitation. Additionally we account for the heterogeneous effects of climatic factors on developed and developing countries by including interactions of the vectors of temperature and precipitation with the "poor" dummy in equations (4) and (5). The dummy takes a value of one if a country is poor and a value of zero otherwise. Corresponding to equations (3) to (5) the estimated specification is:

$$
\begin{aligned}
& \Delta \ln \left(Y_{i t}\right)=\alpha \Delta \ln \left(K_{i t}\right)+\beta \Delta \ln \left(L_{i t}\right)+\eta_{t}+\Delta v_{i t}-\Delta u_{i t} \\
& \Delta \mu_{i t}=\delta_{0}+\delta_{1} \text { Temp }_{i t}+\delta_{2} \text { Precip }_{i t}+\delta_{3} \text { Temp }_{i t} \times \text { Poor }^{\prime}+\delta_{4} \text { Precip }_{i t} \times \text { Poor }^{\prime \prime}+\omega_{i t}
\end{aligned}
$$

\footnotetext{
${ }^{11}$ Relevance of population weighted temperature data over area weighted temperature data for measuring economic impacts is sector specific. For example, if the objective is to measure the impacts on labour productivity then population weighted temperature data may be well suited, but if we are measuring the impacts for agriculture then this might not be the case. We are thankful to one of the reviewers for pointing out this concern.

12 Choice of countries has been restricted by availability of data. For the countries included in the study, see Appendix Table A.

${ }^{13}$ Burke et al. (2015) have considered a country to be poor if its purchasing power parity (PPP) adjusted per capita income was below the global median in 1980. An alternative way is to include yearly per capita income as many countries have progressed and have better capacity to adapt to climatic changes since then. But allowing the classification to vary over time could make it an endogenous variable since the unobservable variables that affect current per capita income could also affect TFP.
} 


$$
\sigma_{\Delta u_{i t}}^{2}=\gamma_{0}+\gamma_{1} \text { Temp }_{i t}+\gamma_{2} \text { Precip }_{i t}+\gamma_{3} \text { Temp }_{i t} \times{ }^{\prime \prime} \text { Poor }^{\prime \prime}+\gamma_{4} \text { Precip }_{i t} \times " \text { Poor }^{\prime \prime}+\varphi_{i t}
$$

where countries are indexed by $i$ and years by $t ; \eta_{t}$ are year fixed effects; Temp $p_{i t}$ and Precip $_{i t}$ are temperature and precipitation variables for country $i$ in year $t$, respectively; $\delta^{\prime} s$ and $\gamma^{\prime} s$ are parameters of the mean and variance functions of inefficiency change; and $\omega$ and $\varphi$ are the error terms.

We retrieve the parameters of stochastic production frontier and the determinants of inefficiency change and its variance, using panel stochastic frontier approach. Greene (2005) proposes 'true fixed effect' models to differentiate between individual heterogeneity and inefficiency. However, 'true fixed effect' models suffer from an incidental parameters problem (Chen et al., 2014). In the case of MLE, although the parameter estimates remain unbiased, 'but the MLE's of the error variances are biased' (Chen et al, 2014, p. 66). In stochastic frontier analysis, the error variances are an essential component of the inefficiency term which is extracted from the composite error term. We apply the first difference-MLE model to estimate the production frontier. First difference-MLE removes the incidental parameters while accounting for time invariant effects before estimation and produces consistent estimates of parameters and error variances for fixed time periods by maximizing the likelihood function (Chen et al. 2014). Moreover, we include time dummies to account for year specific effects (e.g., financial crisis of 2008) rather than time trend. This strategy of controlling for time invariant and time variant effects is robust to mis-measurement of controls (Burke et al., 2015).

We conduct a set of tests to confirm the stationarity properties of the data. We perform firstand second- generation panel unit root tests. Among the first generation tests, we consider two tests namely, Im, Pesaran and Shin (IPS) (2003) and Maddala and Wu (1999). In the second generation tests, we use Pesaran's CIPS test (Pesaran, 2007). Results of these stationarity tests are reported in Appendix Tables A1.1 to A1.3. Using 4 lags, we fail to reject the null hypothesis of a unit root for economic variables (real GDP, capital stock and labour expressed in natural logarithm), but are able to reject the null hypothesis of a unit root for the climatic variables. We find that the economic variables are stationary in first differences.

The test results for cross-sectional dependence (CD) are reported in Appendix Table A2. We conduct the Pesaran's CD test (Pesaran, 2004). First, we run fixed effects panel regressions assuming that the growth rate of GDP is a function of growth rate of capital and labour along with climatic variables. We test the results for cross sectional dependence and reject the null hypothesis of cross-sectional independence. Then, we again run the fixed effects panel regressions by including year dummies and test for cross sectional independence by conducting the Pesaran CD test and fail to reject the null hypothesis.

There are possible concerns regarding endogeneity of regressors in stochastic frontier models (Shee and Stefanou, 2015). A possible source of endogeneity could be that factor input variables may be related to unobserved productivity and climatic variables. We address this concern in two ways: (i) stochastic frontier estimation makes explicit distributional assumption of the unobserved productivity (Van-Biesebroeck, 2008). We assume that the distribution of mean and variance of the unobserved productivity is a function of truly exogenous climatic variables; ${ }^{14}$ and (ii) if one of the regressors is stationary in first difference

\footnotetext{
${ }^{14} \mathrm{We}$ assume that the one-sided error term has a truncated normal distribution.
} 
and the explained and explanatory variables are co-integrated, then least square estimation provides super-consistent slope parameters even if some of the variables are endogenous (O'Donnell, 2016). We conduct Pedroni (2004) and Westerlund (2007) panel co-integration tests and find that the variables are co-integrated (Appendix Tables A3.1 and A3.2).

To test the hypothesis that effects of the climate variables on mean and variance of production inefficiency change are confined to poor countries, we include interaction variables which are the product of average annual temperature and total annual precipitation in a country and the dummy variable "poor". Estimated coefficients of temperature and precipitation variables describe response function for rich countries and coefficients of the interaction terms define adjustments to these parameters that are only applicable for poor countries. This implies that if the response of climatic factors is limited to poor countries then the coefficients of the interaction terms are statistically significant, but not of temperature and precipitation variables. If coefficients of the adjustment factors are not distinguishable from zero, it implies that climatic factors affect both rich and poor countries equally and if the coefficients of both climatic factors and their adjustment factors are statistically significant, it implies that both rich and poor countries are affected, but the response could be different. To capture nonlinearity of temperature effects on economic activities, we parameterize both the mean and variance of one-sided error term by truly exogenous climatic variables and the nonlinearity arises naturally as a result.

Does temperature change affects the level of income or growth rate of income? To answer this question, earlier studies (e.g., Dell et al., 2012) include lags of climatic factors along with their contemporaneous values in the regression equations. Burke et al. (2015) find that the results become noisier as an increasing number of lags of temperature effects are included and uncertainty in cumulative effect increases. This indicates that by using GDP growth as a dependent variable, it is difficult to distinguish between level and growth effects. We model efficiency growth as a one-sided error term and parameterize it by climatic factors and can therefore estimate medium to long-term effects of temperature on economic activities, which are known to be strongly influenced by efficiency growth.

To check robustness, we estimate the stochastic frontier model using data on climatic variables from two different sources. Table A4 reveals that the estimates of stochastic frontier models are almost identical irrespective of the source of climatic data. We also run the base specification using sub-sample of countries excluding Sub-Saharan countries and only for Sub-Saharan countries using both sources of weather data. Using weather data obtained from the World Bank, we run the specification for the sub-sample of 1960-2010, a period covered by BHM data set, and two sub-samples for the time period 1970-2014 and 1990-2014, respectively. All sub-sample levels estimates are qualitatively not different from the estimates obtained for the whole sample (Table A5). The results reported in Table A5 show that the specification results remain robust regardless of the source of weather variable data, period of study or group of countries.

\section{Empirical Results}

Table A4 provides parameter estimates of the stochastic production frontier models. We estimate stochastic frontier models including climatic variables. In all versions, we observe that both $\Delta \sigma_{u}$ and $\Delta \sigma_{v}$ are statistically significant implying that stochastic frontier model specification is appropriate. Magnitudes of the parameters suggest that one-sided error term 
explains more of the overall production variance than the usual error term, implying that growth in output is determined by TFP.

Table A4 (Versions 2 and 4) provide estimates of the stochastic production frontier when the mean and variance of inefficiency term are parameterized by both climatic variables and their interactions with the "poor" dummy. We find that both temperature and precipitation variables are statistically significant. Coefficients of the interaction terms (adjustment factors) explaining the meaning of the one-sided error terms are not different from zero but they are statistically significant in explaining the variance of the one-sided error term. Note that marginal effect of climatic factors depends on the coefficients of both mean and variance terms. This implies that the response of climatic variables is not confined to poor countries. Both poor and rich countries are affected by climatic factors, and the response in poor countries is different from rich countries. We find that production efficiency growth is higher in rich countries in comparison to poor countries. ${ }^{15}$

Our interest lies mainly in estimates of the effect of weather variables on growth and variability of efficiency growth. Parameter estimates of the determinants of mean and variance of one-sided error term are not very informative since they are not marginal effects due to model's nonlinearity. Even the direction of marginal effects of a determinant is difficult to observe from slope coefficients since marginal effects depend on the estimates of both the mean and variance functions of the one-sided error term. Table 1 displays estimates of marginal effects of climatic factors on production inefficiency change and its uncertainty for versions 2 and 4 of the models.

Table 1 reports sample means of the marginal effects on production inefficiency change and its uncertainty. Stochastic frontier estimates reveal that the mean and variance effects of weather variables are not confined to poor or rich countries, therefore, we present the marginal effects according to the location of a country in a particular temperature zone. Note that since the model allows nonlinearity, we present the results for 5-bins: 'very hot' (average annual temperature above $25^{\circ} \mathrm{C}$ ), 'hot' (average annual temperature $20-25{ }^{\circ} \mathrm{C}$ ), 'mild' (average annual temperature $15-20{ }^{\circ} \mathrm{C}$ ), 'cold (average annual temperature $10-15{ }^{\circ} \mathrm{C}$ ), and 'very cold' (average annual temperature below $\left.10{ }^{\circ} \mathrm{C}\right) .{ }^{16}$

A negative sign of the marginal effect of a determinant of mean production inefficiency change indicates that higher levels of that variable are associated with improved production efficiency change. On the other side, a positive sign signals deterioration in production efficiency change. That is, if the sign of the marginal effect of temperature on production inefficiency change alters from negative to positive within a sample, it implies that the relationship between temperature and its effects on production efficiency change is concave. Similarly, a negative sign for the variance equation parameters implies reduced uncertainty in efficiency growth and a positive sign is an indicator of increasing uncertainty.

The sample mean of marginal production inefficiency change effect and its uncertainty effects of temperature are positive implying that a $1{ }^{\circ} \mathrm{C}$ temperature increase reduces

\footnotetext{
${ }^{15}$ Detailed country level panel results of production efficiency are available from the authors.

${ }^{16} 5$-bins classification has been done following Heal and Park (2013) and the classification of countries based on these bins is given in Appendix Table A.
} 
production efficiency growth by about 0.1 percentage points ${ }^{17}$ and increases its uncertainty by 0.06 percentage points (Table 1). The marginal impact of temperature at the bin levels reflect that temperature increase is beneficial for countries that are located in very cold or cold temperature zones but is harmful for countries located in hot or very hot temperature zones. An average country located in a very cold zone benefits due to the temperature increase, however a country located in a very hot temperature zone is negatively affected by about 0.23 percentage points in terms of efficiency growth loss due to a $1{ }^{\circ} \mathrm{C}$ increase in temperature. In mild temperature zone the marginal effect is negligible in magnitude.

Further, to understand nonlinearity in the effects of temperature on efficiency growth and its variability, we present box plots of the marginal effects according to temperature bins (Figure 1). Panel A of the figure displays that detrimental marginal effects on efficiency growth and its variability are negligible for very cold and cold temperature zones, but are more pronounced in hot and very hot regions. It also reveals differences in magnitude of the effects estimated from two different sources of weather data. Note that population weighted data on weather variables picks up economically relevant climate realizations relative to land area based weather variables. On an average basis, we find that the magnitude of these effects is slightly larger when measured using land based temperature relative to population weighted temperature in very cold and cold regions, but the converse is true for hot and very hot regions. In mild temperature regions, the effects are of equal magnitude, irrespective of the measurement of temperature data.

We are also interested in understanding the effects of temperature change on uncertainty. Estimated results reveal that increasing temperature does not only affect efficiency growth but also its variability (Figure 1, Panel B). Magnitude and direction of the marginal effects of temperature on uncertainty exhibit that additional $1{ }^{\circ} \mathrm{C}$ increase in temperature has negligible effects if a country is located in the cold zone but this effect is detrimental and substantial for a country located in hot or very hot climate zone. Combined results of marginal effects of temperature on production efficiency change and its uncertainty predict that, other things being equal, additional increases in temperature in hot or very hot climate zones not only lowers efficiency growth but also makes it less stable than before.

We find that marginal effects of precipitation on efficiency growth are positive though the magnitude of the effect is small. This is observed to be true irrespective of the location of a country (Table 1). A $100 \mathrm{~mm}$ increase in annual total precipitation increases efficiency growth by 0.13 percentage points and reduces the variability.

To understand the level of optimal temperature, we scatter plot the marginal effects in Figure 2. Sign of the marginal effect of temperature alternates from negative to positive as countries move from very cold or cold regime to hot or very hot regime and strengthens in magnitude (Figure 2, Panel A). The marginal effect of temperature on production efficiency growth is equal to zero or negligible somewhere between 12 to $15^{\circ} \mathrm{C}$ of temperature based on weather data obtained from Burke et al (Panel A1) and at about $7-8{ }^{\circ} \mathrm{C}$ for data obtained from the World Bank (Panel A2). This finding corroborates with the findings of Burke et al. (2015). They find that country level productivity peaks at $13{ }^{\circ} \mathrm{C}$ of temperature. The Figure also reveals that at optimal temperature range, not only the efficiency growth touches the peak but

\footnotetext{
${ }^{17}$ Since $\partial \mathrm{E} \Delta \mu \partial \mathrm{T}=-\partial \mathrm{E} \Delta \mathrm{ln}$ y $\partial \mathrm{T}$, the magnitude of marginal effect of 0.1 percentage points translates into a decrease in output growth by 0.1 percentage points.
} 
it also becomes more stable than before (Figure 2, Panel B1). ${ }^{18}$ The discrepancy observed in the optimal temperature level between the two data sets may be attributed to the fact that area weighted temperature is appropriate from a meteorological perspective while the populationweighted temperature reflects the impact of climate on economic activity. For example, in Canada or Russian Federation there is a huge difference in average temperature between the two data-sets. In Canada, $1{ }^{\circ} \mathrm{C}$ population weighted temperature increase enhances production efficiency growth by about 0.01 percentage points and the corresponding marginal effect is 0.006 percentage points due to increases in area weighted temperature (Table A6).

We find that most countries located in very cold temperature zone either benefit from further temperature increases or experience effects that are negligible. However, in hot and very hot countries further increases in temperature is not only detrimental for production efficiency growth but also makes growth rate less stable than before. Figure 3 reveals that countries such as Mongolia (which is the coldest country based on population weighted temperature) benefit from any further temperature increase, but hot countries like Brunei Darussalam have to face the hardest detrimental effects. ${ }^{19}$

Our empirical results of temperature effects on efficiency growth are quite consistent with findings in other studies. For example, Heal and Park (2013) find that $1{ }^{\circ} \mathrm{C}$ increase in contemporaneous temperature in India, Thailand and Nigeria negatively affects per capita output by about 3 to 4 percent whereas a similar increase in temperature increases output in Norway and Sweden significantly. This shows that a concave relationship between temperature and efficiency growth is a good approximation of the underlying relationship.

We observe a positive relationship between temperature level and its marginal effect on mean and variance of production inefficiency. Correlation coefficients between temperature level and its marginal effects on the mean and variance of inefficiency change are 0.90 and 0.92 , respectively for poor countries, but the correlation coefficients are 0.17 and 0.08 , respectively for rich countries. This implies that the marginal effects of rising temperature on production efficiency change and its uncertainty are more detrimental in poor countries. Further, to understand the role of economic development in moderating impacts of temperature change we regress the marginal impacts on temperature and per capita income using the fixed effect model. Regression results in Table 2 reveal that the detrimental marginal impacts are positively related to temperature level but negatively related to per capita income implying that in the same climate zone, economic development moderates the impacts of temperature change.

To further confirm, we plot the relationship between three variables namely, marginal impacts, level of temperature and per capita income (Figure 4) for the sample of countries in which average temperature is less than $25^{\circ} \mathrm{C}$. Note that high income countries located in very hot climate zone are generally oil producing and exporting countries (OPEC) which experience marginal impacts similar to poor countries. Figure 4 confirms that marginal impacts of temperature increase on mean and variance of efficiency growth are higher for those countries that are located in hot regions and are low income countries. This result is

\footnotetext{
${ }^{18}$ Note that we observe a small cluster of points about the optimal zone above the fitted regression line (Panel A1 and Panel B1).These points belong to Bhutan, which is a poor country. It reflects that it is not only the location of a country but also level of development that determines climatic effects on production efficiency growth and its variability.

${ }^{19}$ Average annual marginal effects of temperature on mean and variance of production efficiency growth at the country level are provided in Appendix Table A6 and Figure A1 maps the effects based on temperature (WB).
} 
consistent irrespective of the source of temperature data. These results become shaper as we include poor and very hot countries in the sample (Appendix Figure A2). Our analysis reveals that higher income moderates detrimental temperature effects in countries which observe on average less than $25{ }^{\circ} \mathrm{C}$ temperature. These findings combine the findings of Dell et al. (2012) with the findings of Burke et al. (2015). Reduction in mean efficiency growth is higher for countries in hotter zones and for those with lower per capita income. These countries may have lower growth rates to begin with and so the relative effect is larger for these countries.

\section{Implications of Climate Change for Growth in Production Efficiency}

We quantify potential effects of climate change on production efficiency growth by combining our parameter estimates with projections of future climatic changes under 'business-as-usual' scenarios (Representative Concentration Pathways (RCP)8.5) for the two periods 2020-2040 and 2080-2100. To quantifying the future potential impacts, we assume that economic activities or TFP changes respond to temperature changes in a manner similar to the response observed during 2000-2010.

We obtain the data on future temperature levels during 2020-2040 (short-run) and 2080-2100 (long-run) from the World Bank's Climate Knowledge Portal for scenario RCP8.5 for 129 countries. This portal provides monthly data on temperature and precipitation from 16 different climate models. A combination of predictions, known as ensembling, is expected to perform better than individual prediction (Athey et al. 2019). We use an arithmetic mean of monthly temperature data for these 16 models to obtain yearly average annual temperature. We observe that as compared to 2000-2010, average temperature in $2020-2040$ will be $1.7^{\circ} \mathrm{C}$ higher and in 2080-2100 will be about $4.8^{\circ} \mathrm{C}$ higher.

To project the effect of warming on production efficiency growth, we assume that population weighted temperature change follows the meteorological temperature change pattern. Using parameter estimates derived using BHM temperature dataset, we find that in the short-run and long-run, on an average, production efficiency growth declines by 0.11 and 0.26 percentage points, respectively, while production uncertainty increases by 0.006 and 0.018 percentage points in short-run and long-run temperatures, respectively (Figure 5). The impacts are not uniform across countries if the countries are facing 2020-2040 and 2080-2100 temperature in 2000-2010. Sierra Leone would have been the worst affected as it loses about 3.23 percentage points in TFP growth, but Mongolia gets better off as it would have experienced improvement in TFP growth rate of the magnitude of 0.023 percentage points with higher stability. In the long-run, Sierra Leone will face temperature increase of about 2.7 ${ }^{\circ} \mathrm{C}$ and there will be about $6{ }^{\circ} \mathrm{C}$ increase in temperature in Mongolia. Note that the projected marginal impacts are a function of baseline temperature (Figure 3). ${ }^{20}$ In particular, some European countries and Canada could have benefited from increased average temperatures (Figure 5).

Projected effects show that in short to long run marginal effects of temperature increase would not have been much different in rich countries but would have been more pronounced

\footnotetext{
${ }^{20}$ Projected marginal effects of temperature on the mean and variance of production efficiency growth at country level for short-run and long-run are provided in Appendix Table A7 and Figure A3 maps the projected short-run values.
} 
in poor countries. For example, for the US the effects would be about 0.013 to 0.018 percentage points of loss in production efficiency growth in short-run and long-run temperatures, but in Zimbabwe the effects would have been 0.051 to 0.11 percentage points despite the fact that temperature increase would have been higher in US than in Zimbabwe. Similarly, we observe that India and Bangladesh would have experienced losses in marginal TFP growth of about 0.11 to 0.28 and 0.21 to 0.94 percentage points, respectively, in short to long-run projected temperatures. Note that further increase in temperature is not affecting the variability of TFP growth in US, but growth rate in TFP in poor countries is less stable than before. Some of the developed countries such as Finland would have been benefited from further temperature increase and countries like the United Kingdom would have been the least affected. Overall we find that poor countries are more vulnerable than rich countries though they face similar or lower temperature increase since marginal effects are a function of base level temperature and economic development. Generally, the marginal effects are more pronounced in the countries of South Asia, Sub-Saharan region, OPEC and Latin America both in short-run and long-run.

\section{Discussion and Conclusion}

This paper examines the economy-wide relationship between temperature and production efficiency growth using a one-step stochastic frontier approach for a sample for 168 countries over the period 1950-2014. We examine the marginal effects of temperature on production efficiency growth and uncertainty. We find that an increase in temperature by $1{ }^{\circ} \mathrm{C}$ reduces average efficiency growth while increasing its uncertainty. These effects are larger for poor countries relative to rich countries. The marginal effects of an increase in temperature differ widely across countries depending on the temperature zone and GDP level. At the margin we find that a $1{ }^{\circ} \mathrm{C}$ increase in temperature is beneficial for countries located in cold or very cold temperature zones but it is harmful for countries located in hot or very hot temperature zones. These results show the importance of incorporating nonlinearity in the relationship between temperature and efficiency growth and its implications for heterogeneity in the effects of temperature changes across countries in different temperature zones. Our findings also show that the effects of temperature on efficiency growth are not deterministic, particularly for countries located in hot temperature zones; climate change increases uncertainty in production efficiency growth in these countries. In general we find evidence of a concave relationship between temperature and efficiency growth. We also find increased uncertainty in efficiency growth as temperature increases, particularly in developing countries. It is also found that the adverse effects of climate change are largely due to changes in temperature and that the effect of changes in precipitation on production efficiency are negligible, though beneficial.

Furthermore, our forecast of the impact of potential changes in temperature on production efficiency growth and uncertainty shows the effect is not trivial since it is additional to current impact estimates. Our finding that production efficiency growth declines by 0.11 and 0.26 percentage points, respectively, while production uncertainty increases by 0.006 and 0.018 percentage points in short-run and long-run, respectively. Moyer et al (2014) and Dietz and Stern (2015) show that the trajectory of output is highly sensitive to changes in TFP. Even a small magnitude of TFP damages leads to a substantially different consumption growth path. For example, Moyer et al. (2014) observe that consumption in 2300 reduces by 70 percent relative to the no climate change scenario due to the effects of climate change in TFP growth. 
Estimates of the effects of temperature on productivity are key to determining the climate damage function in IAMs and estimating the social cost of carbon. Most IAMs are developed at a global level or at regional level and assume a common damage function. However, damage functions can be expected to vary across countries depending on current climatic conditions in those countries and their level of development that can influence the ability to mitigate and adapt to those damages. Moreover, these damages due to climate change can be expected to be stochastic and not deterministic as assumed currently in IAMs. Existing empirical evidence of these damage functions and their heterogeneity across countries are limited and sector specific.

Our analysis shows that climate change has dynamic and nonlinear effects on TFP growth and increases uncertainty of future growth possibilities. These effects are more pronounced in poor countries than rich countries. Since marginal effects are a function of base level temperature and level of economic development in a country, we find that in poor countries a further increase in temperature by $1{ }^{\circ} \mathrm{C}$ affects the TFP growth rate by 0.112 percentage points, but in the rich countries the loss is 0.083 percentage points. Moreover, TFP growth is more stochastic in poor countries than rich countries due to temperature increase. The variance of TFP growth increases by about 0.01 percentage points, on average, among both groups of countries.

Our findings contribute to improved understanding of the mechanisms by which climate change affects economic activity. We provide empirical evidence on the magnitude of the impact and how this impact varies across countries which can be directly incorporated in IAMs to improve their predictive capabilities for estimating the social cost of carbon. We show that these effects are non-linear and occur because temperature affects the productivity of labour and capital and these effects differ both across locations and with the level of development of a country. These findings imply that global IAMs should incorporate damage functions that differ across countries. Estimates of climate damages, i.e. social cost of carbon, will also differ across locations based on their current climatic conditions and countryspecific trajectory of changes in temperature. We leave it to future research to use these damage functions to estimate the social cost of carbon at a country-specific level. 


\section{References}

Aigner, D. J., Lovell, C. A. K., Schmidt, P., 1977. Formulation and estimation of stochastic frontier production function models. Journal of Econometrics 6 (1), 21-37.

Athey, S, Bayati, M, Imbens, G, Qu, S, 2019. Ensemble methods for causal effects in panel data settings. NBER Working Paper 25675.

Barreca, A.I., 2012. Climate change, humidity, and mortality in the United States. Journal of Environmental Economics and Management, 63(1), pp.19-34.

Bera, A. K., Sharma, S. C., 1999. Estimating production uncertainty in stochastic frontier production function models. Journal of Productivity Analysis 12(2), 187-210.

Burke, M, Hsiang, SM, Miguel, E, 2015. Global non-linear effect of temperature on economic production. Nature 527, 235-239

Carleton, TA and Hsiang, SM. 2016. Social and economic impacts of climate. Science 353(6304):

Chen, Y-Y., Peter, Schmidt, Hung-Jen, Wang, 2014. Consistent estimation of the fixed effects stochastic frontier model, Journal of Econometrics 181, 65-76.

Dell, Melissa, Jones, Benjamin F, Olken, Benjamin A, 2012. Temperature shocks and economic growth: evidence from the last half century. American Economic Journal: Macroeconomics, 66-95.

Dell, Melissa, Jones, Benjamin F, Olken, Benjamin A, 2014. What do we learn from the weather? The new climate-economy literature. Journal of Economic Literature 52, 740-798

Deschênes, Olivier, Greenstone, Michael, 2007. The economic impacts of climate change: evidence from agricultural output and random fluctuations in weather. American Economic Review, 354-385.

Dietz, S., Stern, N., 2015. Endogenous growth, convexity of damage and climate risk: how Nordhaus' framework supports deep cuts in carbon emissions. Economic Journal 125(583), 574-620.

Forrest, K., Tarroja, B., Chiang, F., AghaKouchak, A. and Samuelsen, S., 2018. Assessing climate change impacts on California hydropower generation and ancillary services provision. Climatic Change, 151(3-4), pp.395-412.

Graff-Zivin, J, Neidell, M. 2014. Temperature and the allocation of time: Implications for climate change. Journal of Labor Economics 32, 1-26

Greene, W.H., 2005. Reconsidering heterogeneity in panel data estimators of the stochastic frontier model, Journal of Econometrics 126, 269-303.

Harrris, I.; Jones, P. D., Osborn, T. J. and Lister, D. H., 2014. Updated high-resolution grids of monthly climatic observations - the CRU TS3.10 Dataset, International Journal of Climatology 34: 623-642

Heal, Geoffrey, Park, Jisung, 2013. Feeling the heat: temperature, physiology \& the wealth of nations, NBER Working Paper

Hsiang, SM, Burke, M, Miguel, E., 2013. Quantifying the influence of climate on human conflict. Science 341: 1235367-1-14

Im, KS, Pesaran, MH, Shin, Y., 2003. Testing for unit roots in heterogeneous panels. Journal of Econometrics 115(1): 53-74.

Letta, Marco, Tol, R. S. J., 2018. Weather, climate and total factor productivity. Environmental and Resource Economics https://doi.org/10.1007/s10640-018-0262-8

Maddala G, Wu S., 1999. A comparative study of unit root tests with panel data and a simple new test. Oxford Bulletin of Economics and Statistics 61: 631-652. 
Mansur, E.T., Mendelsohn, R. and Morrison, W., 2008. Climate change adaptation: A study of fuel choice and consumption in the US energy sector. Journal of Environmental Economics and Management, 55(2), pp.175-193.

Meeusen, W., van den Broeck, J. 1977. Efficiency estimation from Cobb-Douglas production functions with composed error. International Economic Review 18(2), 435-444.

Mendelsohn, R, Nordhaus, WD, Shaw, D., 1994. The impact of global warming on agriculture: A Ricardian analysis. American Economic Review 84, 753-771.

Miljkovic, T., Miljkovic, D. and Maurer, K., 2018. Examining the impact on mortality arising from climate change: important findings for the insurance industry. European Actuarial Journal, 8(2), pp.363-381.

Moore, FC, Diaz DB. 2015. Temperature impacts on economic growth warrant stringent mitigation policy. Nature Climate Change 5: 127-131

Moyer, E., Woolley, M. M., Matteson, N. J., Glotter, M. M., Weisbach, D. 2014. Drivers of uncertainty in the Social Cost of Carbon. Journal of Legal Studies 43, 401-425.

Nordhaus, WD., 2011. The economics of tail events with an application to climate change. Review of Environmental Economics and Policy, 5(2), 240-57.

O'Donnell C., 2016. Using information about technologies, markets and firm behaviour to decompose a proper productivity index. Journal of Econometrics 190: 328-340.

Ortiz-Bobea, A, Knippenberg, E, Chambers, RG, 2018. Growing climatic sensitivity of U.S. agricultural linked to technological change and regional specialization. Science Advances 4(12): 1-9.

Pedroni P., 2004. Panel co-integration: asymptotic and finite sample properties of pooled time series tests with an application to the PPP hypothesis. Economic Theory. 20: 597-625.

Pérez-Lombard, L., Ortiz, J. and Pout, C., 2008. A review on buildings energy consumption information. Energy and Buildings, 40(3), pp.394-398.

Pesaran, M. H., 2004. General diagnostic tests for cross section dependence in panels. University of Cambridge, Faculty of Economics, Cambridge Working Papers in Economics No. 0435.

Pesaran, M.H., 2007. A simple panel unit root test in the presence of cross-section dependence. Journal of Applied Econometrics 22(2): 265-312.

Pindyck, R. S., 2011. Fat tails, thin tails, and climate change policy. Review of Environmental Economics and Policy 5 (2), 258-74.

Pretis F, Schwarz M, Tang K, Haustein K, Allen MR., 2018. Uncertain impacts on economic growth when stabilizing global temperatures at $1.5^{\circ} \mathrm{C}$ or $2^{\circ} \mathrm{C}$ warming. Phil. Trans. $R$. Soc. A 376

Schlenker, Wolfram, Roberts, Michael J., 2009. Nonlinear temperature effects indicate severe damages to us crop yields under climate change. Proceedings of National. Academic. Sciences 106(37), 15594-15598.

Shee A, Stefanou S. 2015. Endogeneity corrected stochastic production frontier and technical efficiency. American Journal of Agricultural Economics 97: 939-952.

Syverson, Chad, 2011. What determines productivity? Journal of Economic Literature 49 (2), 326-365.

Tisgaris P, Wood, J. 2016 A simple climate-Solow model for introducing the economics of climate change to undergraduate students. International Review of Economics Education, 23: 65-81

Tol R., 2017. Population and trends in the global mean temperature. Atmósfera 30, 121-135. 
Urban, DW, Roberts, M.J., Schlenker, W., Lobell, D.B., 2012. Projected temperature changes indicate significant increase in inter-annual variability of US maize yields. Climatic Change 112(2), 525-533.

Van Biesebroeck, J. 2008. The sensitivity of productivity estimates: revisiting three important debates, Journal of Business and Economic Statistics, 26(3) 311-328

Wang, H-J, Schmidt, P. 2002. One-step and two-step estimation of the effects of exogenous variables on technical efficiency levels. Journal of Productivity Analysis 18, 129-144

Wang, H-J., 2003. A stochastic frontier analysis of financing constraints on investment: the case of financial liberalization in Taiwan. Journal of Business and Economic Statistics $21,406-419$

Wang, H. -J., 2002. Heteroscedasticity and non-monotonic efficiency effects of a stochastic frontier model. Journal of Productivity Analysis.18 (3), 241-53.

Weitzman, Martin L., 2011. Fat-tailed uncertainty in the economics of catastrophic climate change. Review of Environmental Economics and Policy5 (2): 275-92.

Wenz, A. and Leverman, A. 2016. Enhanced economic connectivity to foster heat stressrelated losses. Sci. Adv. 2, e1501026

Westerlund, J. 2007. Testing for error correction in panel data. Oxford Bulletin of Economics and Statistics 69: 709-748.

Willner, N, Otto, C, and Leverman A. 2018. Global economic response to river floods. Nature Climate Change 8: 594-598.

Yunfeng, Y. and Laike, Y., 2010. China's foreign trade and climate change: A case study of CO2 emissions. Energy policy, 38(1), pp.350-356.

Zhang P, Deschenes O, Meng K, Zhang J (2018) Temperature effects on productivity and factor reallocation: evidence from a half million Chinese manufacturing plants. Journal of Environmental Economics and Management 88(2018):1-17 
Table1: Marginal effects of climatic variables on the mean and variance of TFP growth (percentage points).

\begin{tabular}{|c|c|c|c|c|c|c|c|c|c|}
\hline \multirow[t]{2}{*}{ Temperature bin } & & \multicolumn{2}{|c|}{ Temperature (BHM) } & \multicolumn{2}{|c|}{ Temperature (WB) } & \multicolumn{2}{|c|}{ Precipitation (BHM) } & \multicolumn{2}{|c|}{ Precipitation (WB) } \\
\hline & & On $\mathrm{E}(\Delta \mathrm{u})$ & On V $(\Delta \mathrm{u})$ & On $\mathrm{E}(\Delta \mathrm{u})$ & On V $(\Delta \mathrm{u})$ & On $\mathrm{E}(\Delta \mathrm{u})$ & On V $(\Delta \mathrm{u})$ & $\mathrm{On} \mathrm{E}(\Delta \mathrm{u})$ & On V $(\Delta \mathrm{u})$ \\
\hline \multirow[t]{2}{*}{ Very Cold } & Mean & $-0.0045^{* * *}$ & $-0.0004^{* * *}$ & $0.0106^{* * *}$ & $0.0005^{* * *}$ & $-0.0017^{* *}$ & $-0.0001^{* *}$ & $-0.0014^{*}$ & $-0.0001^{*}$ \\
\hline & Std. Dev. & 0.0129 & 0.0009 & 0.0067 & 0.0004 & 0.0003 & 0.0000 & 0.0003 & 0.0000 \\
\hline \multirow[t]{2}{*}{ Cold } & Mean & $0.0215^{* * *}$ & $0.0012^{* * * *}$ & $0.0212^{* * *}$ & $0.0012^{* * *}$ & $-0.0015^{* *}$ & $-0.0001^{* *}$ & $-0.0014^{* * *}$ & $-0.0001^{*}$ \\
\hline & Std. Dev. & 0.0235 & 0.0012 & 0.0040 & 0.0003 & 0.0003 & 0.0000 & 0.0003 & 0.0000 \\
\hline \multirow[t]{2}{*}{ Mild } & Mean & $0.0386^{* * *}$ & $0.0025^{* * *}$ & $0.0389^{* * * *}$ & $0.0024^{* * *}$ & $-0.0017^{* *}$ & $-0.0001^{* *}$ & $-0.0014^{* * *}$ & $-0.0001^{* *}$ \\
\hline & Std. Dev. & 0.0161 & 0.0013 & 0.0053 & 0.0006 & 0.0003 & 0.0000 & 0.0003 & 0.0000 \\
\hline \multirow[t]{2}{*}{ Hot } & Mean & $0.0967^{* * *}$ & $0.0055^{* * *}$ & $0.0612^{* * *}$ & $0.0032^{* * *}$ & $-0.0012^{* * *}$ & $-0.0001^{* * *}$ & $-0.0011^{* * *}$ & $-0.0001^{*}$ \\
\hline & Std. Dev. & 0.0917 & 0.0092 & 0.0285 & 0.0011 & 0.0004 & 0.0000 & 0.0004 & 0.0000 \\
\hline \multirow[t]{2}{*}{ Very Hot } & Mean & $0.2269^{* * * *}$ & $0.0156^{* * *}$ & $0.1040^{\text {**** }}$ & $0.0062^{* * * *}$ & $-0.0010^{* * *}$ & $-0.0001^{* * *}$ & $-0.0009^{* * *}$ & $-0.0001^{* *}$ \\
\hline & Std. Dev. & 0.7726 & 0.0976 & 0.4060 & 0.0504 & 0.0022 & 0.0003 & 0.0025 & 0.0003 \\
\hline \multirow[t]{2}{*}{ Total } & Mean & $0.0961^{* * *}$ & $0.0062^{* * *}$ & $0.0562^{* * * *}$ & $0.0032^{* * * *}$ & $-0.0013^{* *}$ & $-0.0001^{* *}$ & $-0.0011^{* *}$ & $-0.0001^{* *}$ \\
\hline & Std. Dev. & 0.4150 & 0.0514 & 0.2207 & 0.0271 & 0.0012 & 0.0001 & 0.0014 & 0.0002 \\
\hline
\end{tabular}

Note: Countries are classified into 5-bins: 'very hot' (average annual temperature above $25^{\circ} \mathrm{C}$ ), 'hot' (average annual temperature 20 - $25^{\circ} \mathrm{C}$ ), 'mild' (average annual temperature $15-20^{\circ} \mathrm{C}$ ), 'cold (average annual temperature $10-15^{\circ} \mathrm{C}$ ), and 'very cold' (average annual temperature below $10^{\circ} \mathrm{C}$ ). Sample includes all countries for which the complete panel data on both climate and economic variables is available for at least seventeen years. Classification of countries according to temperature bins is given in Appendix Table A. Standard errors (SE) are computed using the delta method.

*** Significant at the 1 percent level.

${ }^{* * *}$ Significant at the 5 percent level.

*Significant at the 10 percent level 
Table 2: Relationship between the marginal impacts and temperature and per capita income

\begin{tabular}{|l|r|r|r|r|}
\hline & \multicolumn{2}{|l|}{$\begin{array}{l}\text { Weather variables are } \\
\text { taken from Burke et al. } \\
(2015)\end{array}$} & \multicolumn{2}{l|}{$\begin{array}{l}\text { Weather variables are } \\
\text { taken from World } \\
\text { Bank }\end{array}$} \\
\hline & \multicolumn{1}{|l|}{ Mean } & \multicolumn{1}{l|}{ Variance } & \multicolumn{1}{l|}{ Mean } & Variance \\
\hline Temperature & $0.02264^{* *}$ & $0.00234^{*}$ & 0.00503 & 0.00034 \\
\hline & $(2.39)$ & $(1.92)$ & $(1.14)$ & $(0.61)$ \\
\hline Per Capita Income & $-0.00143^{* *}$ & $-0.00019^{* *}$ & -0.00006 & -0.00001 \\
\hline & $(-2.00)$ & $(-2.04)$ & $(-0.20)$ & $(-0.34)$ \\
\hline Constant & $-0.30749^{*}$ & -0.03493 & -0.03730 & -0.00299 \\
\hline & $(-1.76)$ & $(-1.55)$ & $(-0.46)$ & $(-0.29)$ \\
\hline F Stat & $4.1^{* *}$ & $3.31^{* *}$ & 0.65 & 0.2 \\
\hline DF & $(2,6012)$ & $(2,6012)$ & $(2,7782)$ & $(2,7782)$ \\
\hline Countries & 153 & 153 & 168 & 168 \\
\hline Observations & 6167 & 6167 & 7952 & 7952 \\
\hline
\end{tabular}

Note: the Dependent variables are the marginal effects of temperature on mean and variance of inefficiency growth expressed in percentage points. Temperature is measured in ${ }^{\circ} \mathrm{C}$ and per capita income is measured in thousand 2011US\$ expressed in purchasing power parity (PPP). Figures in parentheses are t-statistics.

${ }^{* * *}$ Significant at the 1 percent level.

${ }^{* *}$ Significant at the 5 percent level.

*Significant at the 10 percent level 
Figure 1: Non-linear marginal effects of temperature on the average rate of growth of production efficiency and on the variance of efficiency growth (by temperature bins)

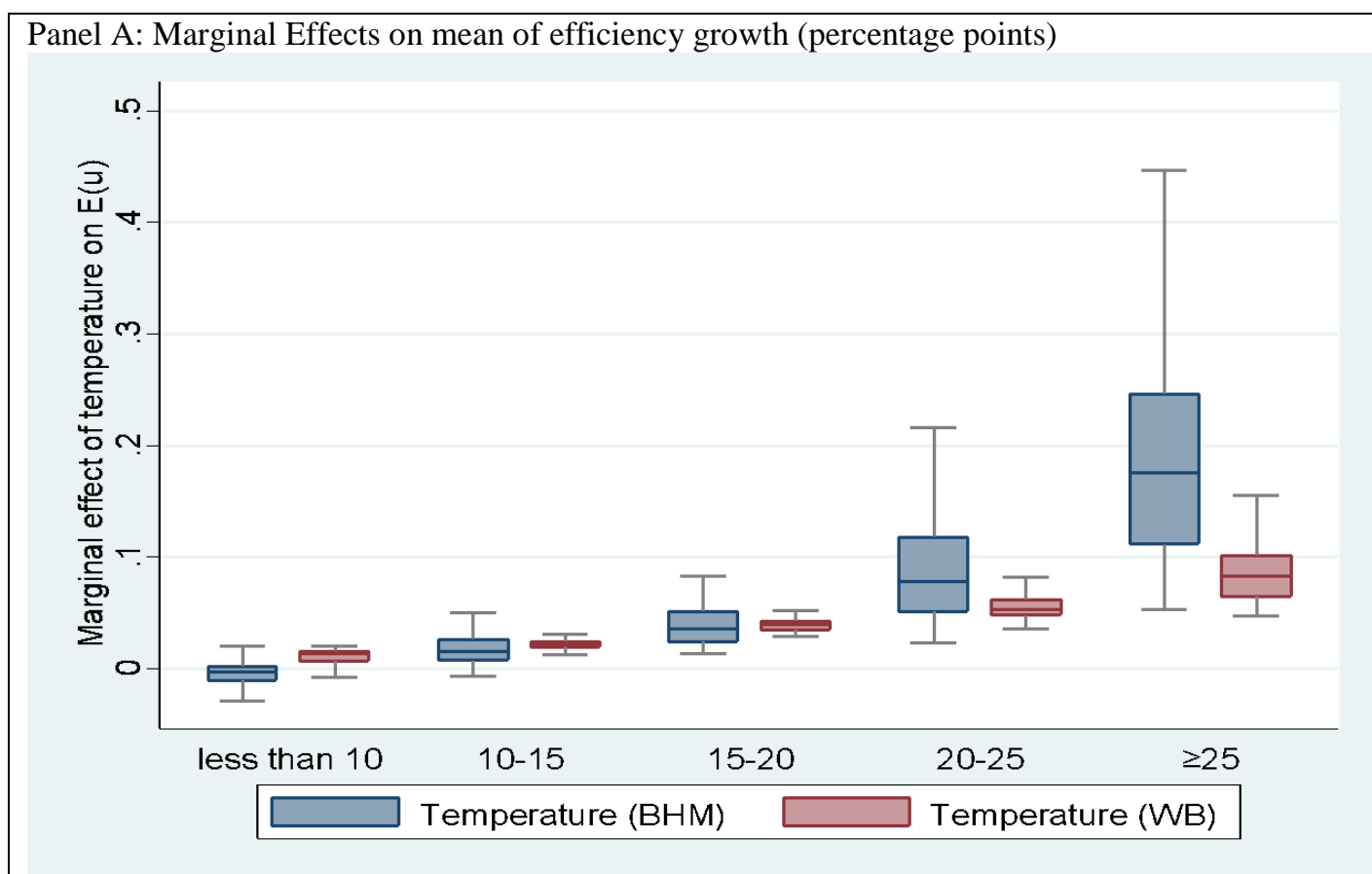

Panel B: Marginal Effects on variance of efficiency growth (percentage points)

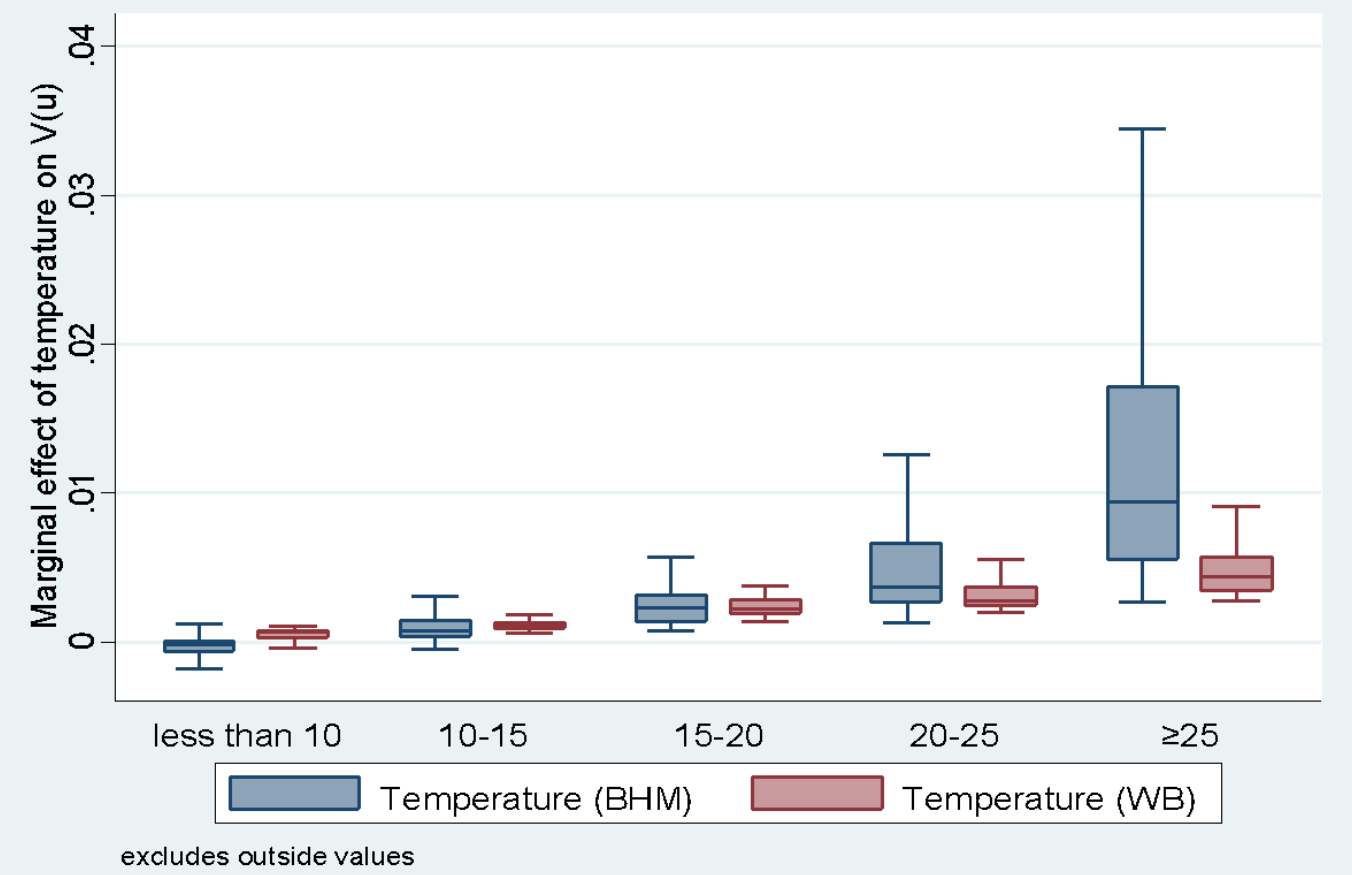

Note: Countries are classified into 5-bins: 'very hot' (average annual temperature above $25^{\circ} \mathrm{C}$ ), 'hot' (average annual temperature $20-25^{\circ} \mathrm{C}$ ), 'mild' (average annual temperature $15-20^{\circ} \mathrm{C}$ ), 'cold (average annual temperature $10-15^{\circ} \mathrm{C}$ ), and 'very cold' (average annual temperature below $10^{\circ} \mathrm{C}$ ). Classification of countries according to temperature bins is given in the Appendix Table A. 
Figure 2: Marginal effects of temperature on efficiency growth and variability (percentage points)

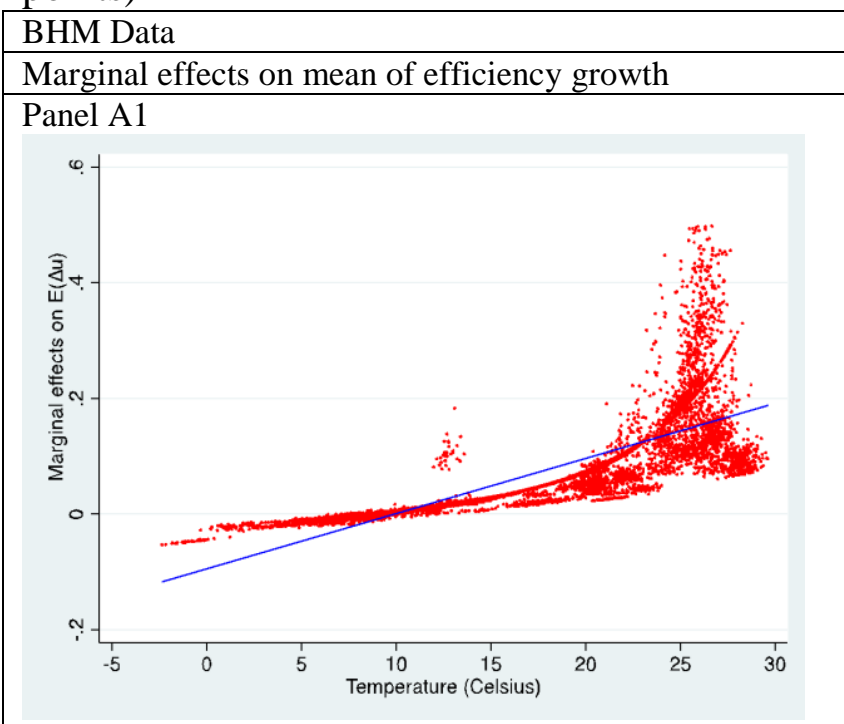

WB Data

Marginal effects on mean of efficiency growth

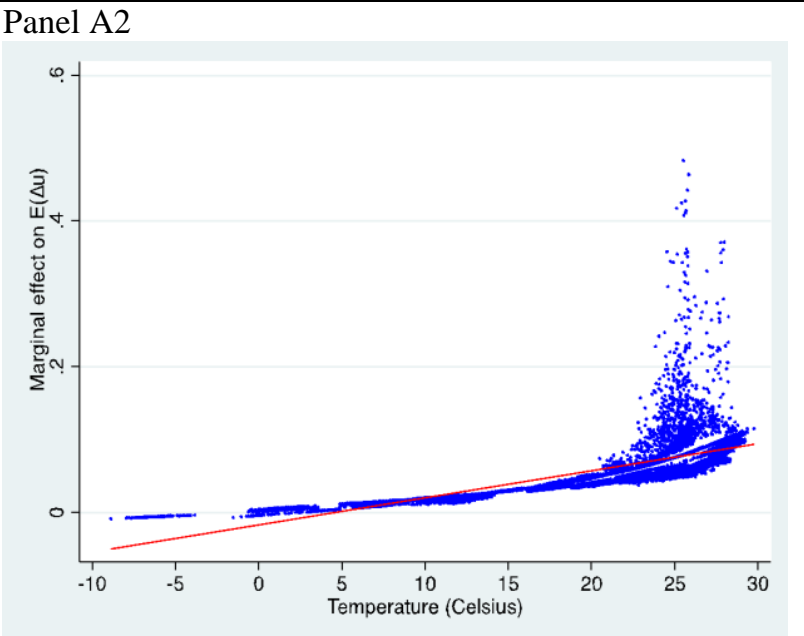

Marginal Effects on variance of efficiency growth

\section{Panel B1}

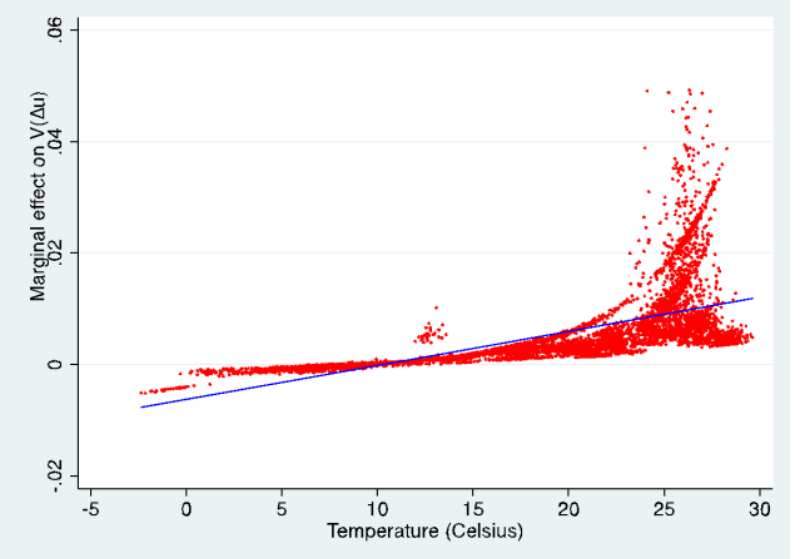

Panel B2

Note: Red color: temperature source Burke et al. (2015); Blue color: temperature source World Bank. Panels A1 and $\mathrm{B} 1$ show that marginal effects of temperature on production efficiency growth and its variance are equal to zero or negligible somewhere between 12 to $15^{\circ} \mathrm{C}$. Similarly Panels A2 and B2 show that optimal temperature is at about $7-8^{\circ} \mathrm{C}$. 
Figure 3: Regional distribution of marginal effects of temperature (BHM) on production inefficiency growth (percentage points)

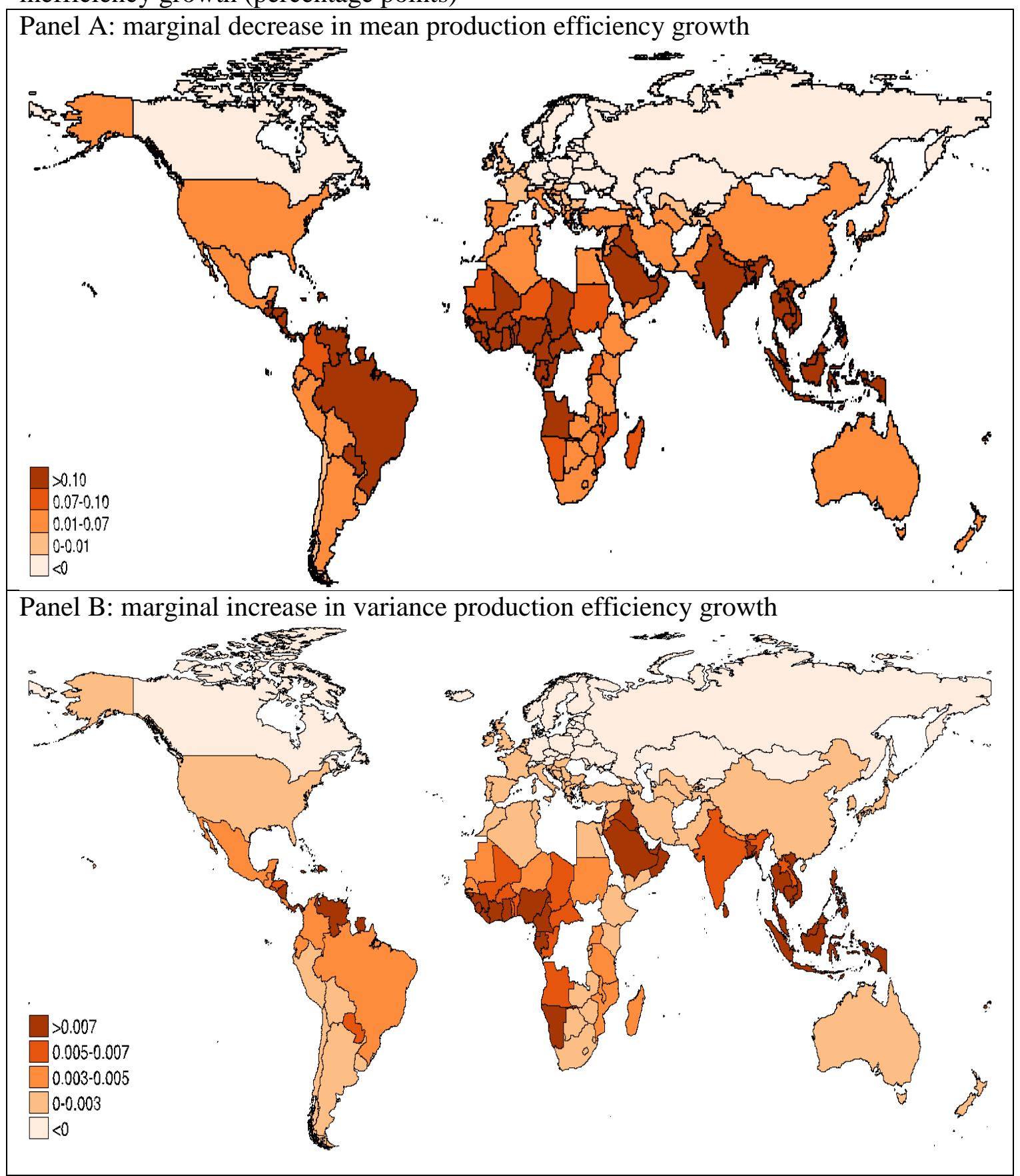

Note: Hotter than average temperature is not only detrimental to production efficiency growth but also makes the growth more variable than otherwise and these effects are larger in very hot countries with average annual temperature greater than $25{ }^{\circ} \mathrm{C}$. Countries such as Mongolia benefit from any further temperature increase, but hot countries like Brunei Darussalam have to face the hardest detrimental effects. 
Figure 4: Marginal effects of temperature and level per-capita income on the mean and variance of average efficiency growth (percentage points)

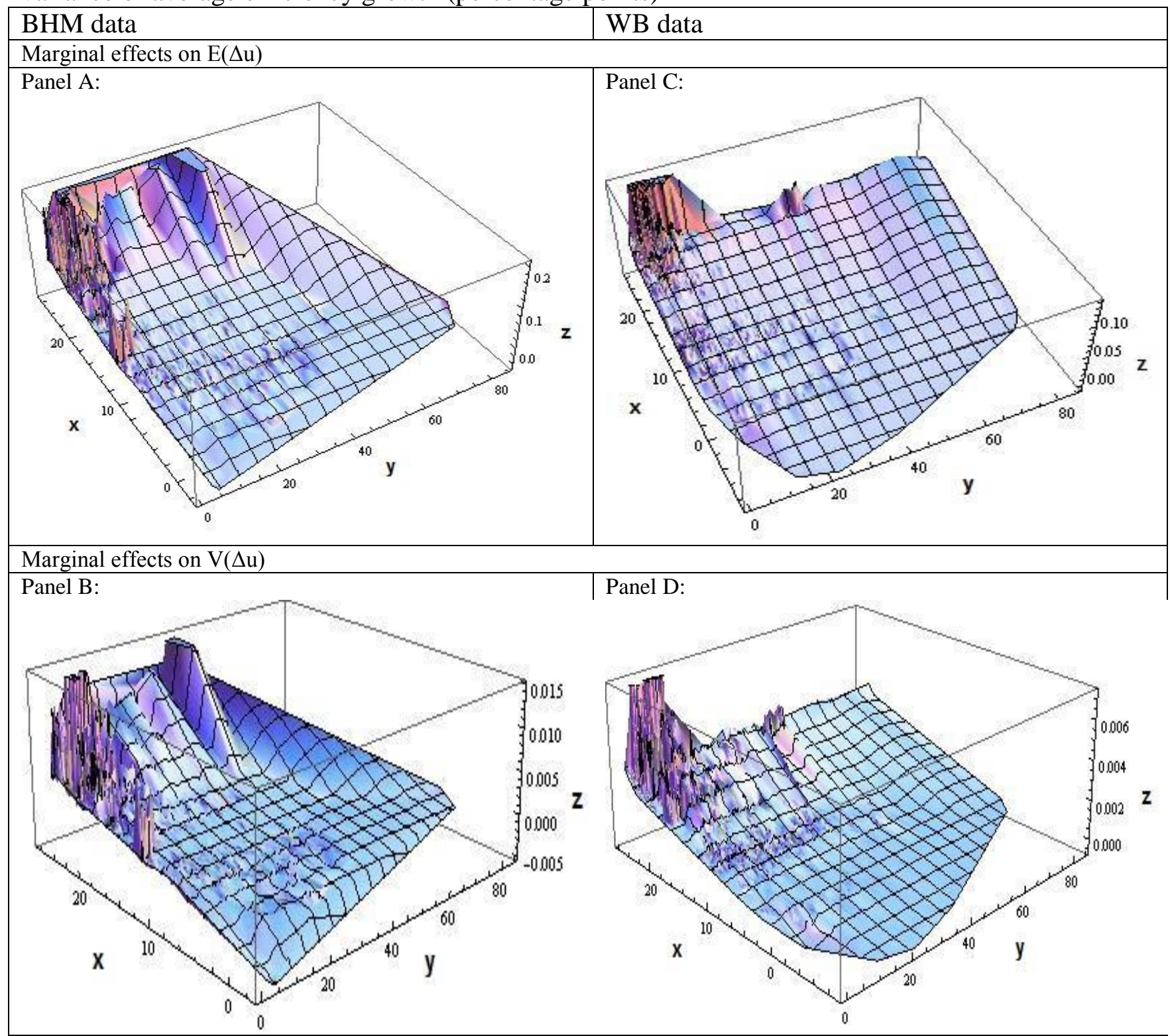

Notes: $\mathrm{x}$-axis measures temperature in ${ }^{\circ} \mathrm{C}$; $\mathrm{y}$-axis measures per capita income in thousand $2011 \mathrm{US} \$$ in terms of PPP; and z-axis measures the marginal effect of temperature change on mean inefficiency growth. The effects are higher in high temperature and low income countries, i.e., higher income moderates detrimental temperature effects in countries which observe on average less than $25^{\circ} \mathrm{C}$ temperature..$^{21}$

${ }^{21}$ In the formulation of these figures following countries information is not included: Countries with average temperature (WB) > 25: Aruba, Anguilla, United Arab Emirates, Benin, Burkina Faso, Bangladesh, Bahrain, Bahamas, Belize, Brazil, Barbados, Brunei Darussalam, Central African Republic, Cote D' Ivoire, Comoros, Cayman Islands, Djibouti, Gabon, Ghana, Guinea, Gambia, Guinea-Bissau, Indonesia, Jamaica, Cambodia, Kuwait, Liberia, Saint Lucia, Sri Lanka, Maldives, Mali, Mauritania, Malaysia, Niger, Nigeria, Nicaragua, Oman, Panama, Philippines, Qatar, Saudi Arabia, Sudan (Former), Senegal, Singapore, Sierra Leone, Suriname, Seychelles, Chad, Togo, Thailand, Trinidad and Tobago, St. Vincent and the Grenadines, Bolivarian Republic of Venezuela. Countries with average temperature (BHM) > 25: United Arab Emirates, Benin, Burkina Faso, Bangladesh, Bahamas, Belize, Brazil, Brunei Darussalam, Central African Republic, Cote D' Ivoire, Congo, Comoros, Dominican Republic, Djibouti, Gabon, Ghana, Guinea, Gambia, Guinea-Bissau, Indonesia, India, Cambodia, Kuwait, Liberia, Sri Lanka, Mali, Mauritania, Malaysia, Niger, Nigeria, Nicaragua, Oman, Panama, Philippines, Qatar, Saudi Arabia, Sudan (Former), Senegal, Sierra Leone, Suriname, Sao Tome 
Figure 5: Projected marginal effects based on 2080-2100 temperatures (percentage points)

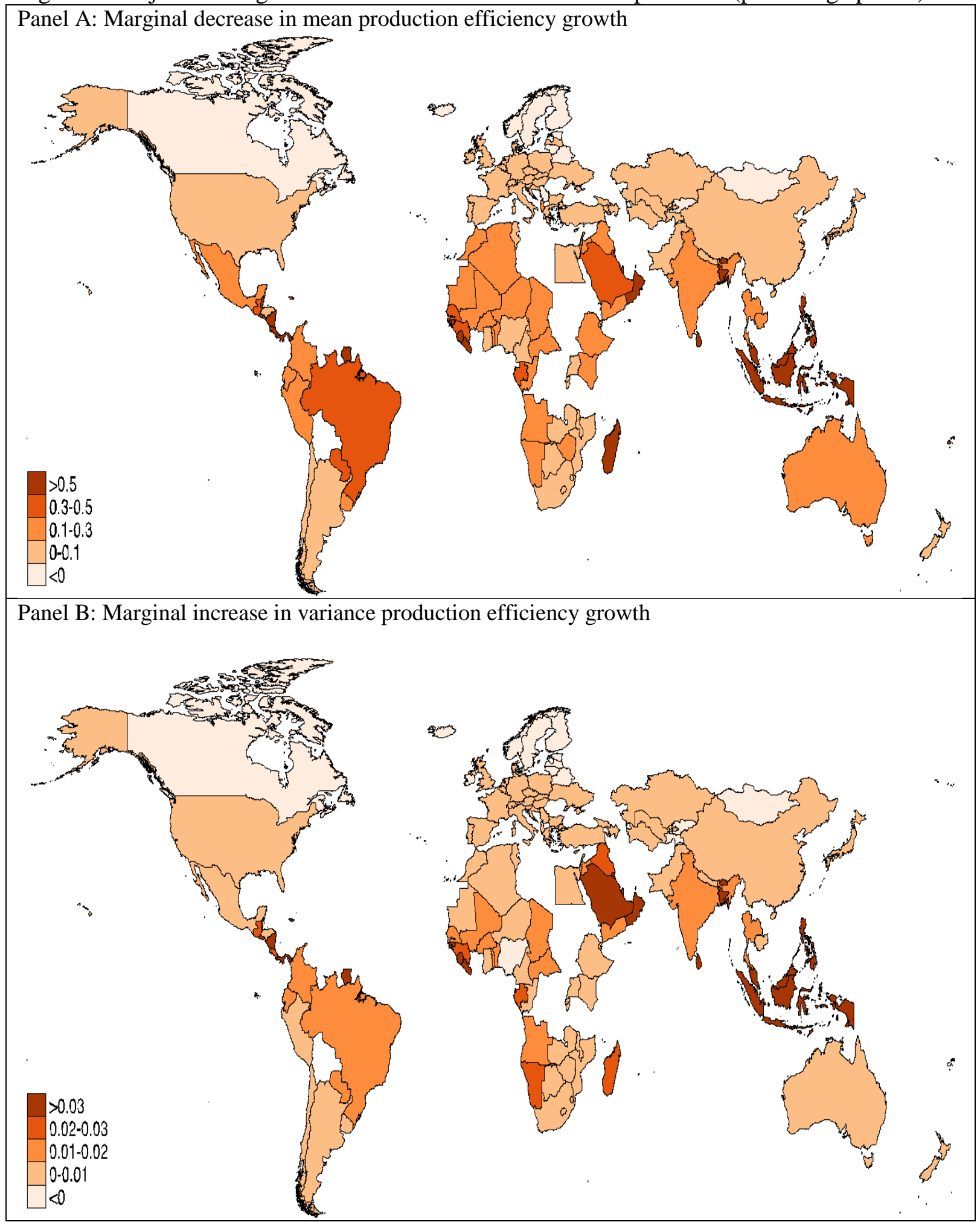

Note: Poor countries are more vulnerable than rich countries though they face similar or lower temperature increase since marginal effects are a function of base level temperature and economic development. The marginal effects are more pronounced in the countries of South Asia, Sub-Saharan region, OPEC and Latin America.

and Principe, Chad, Togo, Thailand, Trinidad and Tobago, St. Vincent and the Grenadines, Bolivarian Republic of Venezuela. Since these countries experience identical temperature effects irrespective of their level of economic development. 


\section{Appendix}

\section{Estimating Marginal Effects of Temperature on the Mean and Variance of Production Efficiency Growth:}

To estimate the marginal effects of temperature on production efficiency growth and its variance we follow (Wang, 2002; 2003). The unconditional mean and variance of production inefficiency change are:

$E\left(\Delta u_{i t}\right)=\sigma_{\Delta u_{i t}}\left[\Lambda+\frac{\phi(\Lambda)}{\Phi(\Lambda)}\right]$

and

$V\left(\Delta u_{i t}\right)=\sigma_{\Delta u_{i t}}^{2}\left[1-\Lambda\left[\frac{\phi(\Lambda)}{\Phi(\Lambda)}\right]-\left[\frac{\phi(\Lambda)}{\Phi(\Lambda)}\right]^{2}\right]$

where $\Delta \mu_{i t}$ and $\sigma_{\Delta u_{i t}}^{2}$ are the mean and variance of production inefficiency; $\Lambda=\Delta \mu_{i t} / \sigma_{\Delta u_{i t}}$; and $\phi$ and $\Phi$ are the probability and cumulative density functions of a standard normal distribution, respectively. The marginal effects of temperature and precipitation can be derived by differentiating (a1) and (a2) with respect to these variables. With tedious maniputation the formula of marginal effects on mean production inefficeincy change is obtained as follows:

$\frac{\partial\left[E\left(\Delta u_{i t}\right)\right]}{\partial z[k]}=\delta[k]\left[1-\Lambda\left[\frac{\phi(\Lambda)}{\Phi(\Lambda)}\right]-\left[\frac{\phi(\Lambda)}{\Phi(\Lambda)}\right]^{2}\right]+\gamma[k] \frac{\sigma_{\Delta u_{i t}}}{2}\left[\left(1+\Lambda^{2}\right)\left[\frac{\phi(\Lambda)}{\Phi(\Lambda)}\right]+\Lambda\left[\frac{\phi(\Lambda)}{\Phi(\Lambda)}\right]^{2}\right](\mathrm{a} 3)$

where $\delta[k]$ and $\gamma[k]$ are corresponding slope coefficients in equations (4) and (5), and $z[k]$ denotes the $k t h$ element of the determinants, i.e., temperature or precipitation. Similarly, the formula of marginal effect of temperature or precipitation on variance of production inefficiency is obtained as:

$\frac{\partial\left[V\left(\Delta u_{i t}\right)\right]}{\partial z_{i t}}=\frac{\delta[k]}{\sigma_{\Delta u_{i t}}}\left[\frac{\phi(\Lambda)}{\Phi(\Lambda)}\right]\left(\left[E\left(\Delta u_{i t}\right)\right]^{2}-V\left(\Delta u_{i t}\right)\right)+\gamma[k] \sigma_{\Delta u_{i t}}^{2}\left\{1-\frac{1}{2}\left[\frac{\phi(\Lambda)}{\Phi(\Lambda)}\right]\left(\Lambda+\Lambda^{3}+\right.\right.$ $\left.\left.\left(2+3 \Lambda^{2}\right)\left[\frac{\phi(\Lambda)}{\Phi(\Lambda)}\right]+2 \Lambda\left[\frac{\phi(\Lambda)}{\Phi(\Lambda)}\right]^{2}\right)\right\} \quad(\mathrm{a} 4)$

where $\frac{\partial\left[V\left(\Delta u_{i t}\right)\right]}{\partial z_{i t}}$ can be interpreted as an estimator of the partial effect of climatic factors production uncertainty. 
Table A: Countries in the sample according to the classification of temperature bins

\begin{tabular}{l} 
Weather variables are taken from the World Bank (Total Countries 168) \\
\hline Less than $10^{\circ} \mathrm{C}$ : Armenia, Austria, Belarus, Belgium, Canada, Chile, China, Czech Republic, \\
Denmark, Estonia, Finland, Georgia, Germany, Iceland, Ireland, Kazakhstan, Kyrgyzstan, Latvia, \\
Lithuania, Luxembourg, Mongolia, Montenegro, Netherlands, New Zealand, Norway, Poland, \\
Russian Federation, Slovakia, Slovenia, Sweden, Switzerland, Tajikistan, Ukraine, United, \\
Kingdom, United States
\end{tabular}

$10{ }^{\circ} \mathrm{C}$ to $15^{\circ} \mathrm{C}$ : Albania, Argentina, Azerbaijan, Bhutan, Bosnia and Herzegovina, Bulgaria, Croatia, France, Greece, Hungary, Italy, Japan, Lesotho, Nepal, Portugal, Republic of Korea, Republic of Moldova, Serbia, Spain, TFYR of Macedonia, Turkey, Uzbekistan

$15^{\circ} \mathrm{C}$ to $20^{\circ} \mathrm{C}$ : Cyprus, Iran (Islamic Republic), Israel, Jordan, Lebanon, Malta, Morocco, Peru, Rwanda, South Africa, Syrian Arab Republic, Tunisia, Turkmenistan, Uruguay

$20^{\circ} \mathrm{C}$ to $25^{\circ} \mathrm{C}$ : Algeria, Angola, Australia, Bermuda, Bolivia (Plurinational State of), Botswana, Burundi, Cabo Verde, Cameroon, China, Macao SAR, Colombia, Congo, Costa Rica, Dominican Republic, Ecuador, Egypt, El Salvador, Equatorial Guinea, Ethiopia, Fiji, Guatemala, Haiti, Honduras, India, Iraq, Kenya, Lao People's DR, Madagascar, Malawi, Mauritius, Mexico, Mozambique, Myanmar, Namibia, Pakistan, Paraguay, Sao Tome and Principe, Swaziland, U.R. of Tanzania, Uganda, Viet Nam, Yemen, Zambia, Zimbabwe

More than $25^{\circ} \mathrm{C}$ : Anguilla, Aruba, Bahamas, Bahrain, Bangladesh, Barbados, Belize, Benin, Brazil, Brunei Darussalam, Burkina Faso, Cambodia, Cayman Islands, Central African Republic, Chad, Comoros, Côte d'Ivoire, Djibouti, Gabon, Gambia, Ghana, Guinea, Guinea-Bissau, Indonesia, Jamaica, Kuwait, Liberia, Malaysia, Maldives, Mali, Mauritania, Nicaragua, Niger, Nigeria, Oman, Panama, Philippines, Qatar, Saint Lucia, Saudi Arabia, Senegal, Seychelles, Sierra Leone, Singapore, Sri Lanka, St. Vincent and the Grenadines, Sudan (Former), Suriname, Thailand, Togo, Trinidad and Tobago, United Arab Emirate, Venezuela (Bolivia)

\section{Weather variables are taken from BHM (Total Countries 153)}

Less than $10^{\circ} \mathrm{C}$ : Armenia, Austria, Belarus, Belgium, Bosnia and Herzegovina, Canada, Chile, Czech Republic, Denmark, Estonia, Finland, Germany, Iceland, Ireland, Kazakhstan, Kyrgyzstan, Latvia, Lithuania, Luxembourg, Mongolia, Netherlands, Norway, Poland, Republic of Moldova, Russian, Federation, Slovakia, Slovenia, Sweden, Switzerland, TFYR of Macedonia, Ukraine, United Kingdom

$10^{\circ} \mathrm{C}$ to $15^{\circ} \mathrm{C}$ : Albania, Azerbaijan, Bhutan, Bulgaria, China, Croatia, France, Georgia, Greece, Hungary, Italy, Japan, Lebanon, Lesotho, New Zealand, Republic of Korea, Serbia, Spain, Tajikistan, Turkey, United States, Uzbekistan

$15^{\circ} \mathrm{C}$ to $20^{\circ} \mathrm{C}$ : Algeria, Argentina, Australia, Bolivia (Plurinational State of), Cyprus, Ecuador, Ethiopia, Iran (Islamic Republic), Jordan, Kenya, Mexico, Morocco, Peru, Portugal, South Africa, Syrian Arab Republic, Tunisia, Turkmenistan, Uruguay

$20^{\circ} \mathrm{C}$ to $25^{\circ} \mathrm{C}$ : Angola, Botswana, Brazil, Burundi, Cabo Verde, Cameroon, Colombia, Costa Rica, Egypt, El Salvador, Equatorial Guinea, Fiji, Guatemala, Honduras, Iraq, Israel, Jamaica, Lao People's DR, Madagascar, Malawi, Mauritius, Mozambique, Namibia, Nepal, Pakistan, Paraguay, Rwanda, Swaziland, U.R. of Tanzania, Uganda, Viet Nam, Yemen, Zambia, Zimbabwe

More than $25^{\circ} \mathrm{C}$ : Anguilla, Aruba, Bahamas, Bahrain, Bangladesh, Barbados, Belize, Benin, Bermuda, Brunei Darussalam, Burkina Faso, Cambodia, Cayman Islands, Central African Republic, Chad China Macao SAR, Comoros, Congo, Côte d'Ivoire, Djibouti, Dominican Republic, Gabon, Gambia, Ghana, Guinea, Guinea-Bissau, Haiti, India, Indonesia, Kuwait, Liberia, Malaysia, Maldives, Mali, Malta, Mauritania, Montenegro, Myanmar, Nicaragua, Niger, Nigeria, Oman, 
Panama, Philippines, Qatar, Saint, Lucia, Sao Tome and Principe, Saudi Arabia, Senegal, Seychelles, Sierra Leone, Singapore, Sri Lanka, St. Vincent and, Sudan (Former), Suriname, Thailand, Togo, Trinidad and Tobago, United Arab Emirate, Venezuela (Bolivia) 
Table A1: Descriptive statistics

\begin{tabular}{|c|c|c|c|c|c|c|}
\hline Variable & Obs & Unit & Mean & Std. Dev. & Min & Max \\
\hline \multicolumn{7}{|l|}{ All Countries } \\
\hline Real GDP at constant 2011 national prices & 7,952 & Million 2011US\$ & 323293 & 1090965 & 42.11 & $1.72 \mathrm{e}+07$ \\
\hline Capital stock GDP at constant 2011 national prices & 7,952 & Million 2011US\$ & 1044899 & 3578327 & 317.68 & $6.76 \mathrm{e}+07$ \\
\hline Number of persons engaged (Employment) & 7,952 & Millions & 14.50 & 57.5 & .001 & 798.37 \\
\hline Temperature (BHM) & 6,167 & Celsius $\left({ }^{0} \mathrm{C}\right)$ & 18.66 & 7.30 & -2.37 & 29.61 \\
\hline Precipitation (BHM) & 6,167 & Millimeters (mm) & 1088.09 & 698.27 & 5.38 & 4877.74 \\
\hline Temperature (WB) & 7,952 & Celsius $\left({ }^{0} \mathrm{C}\right)$ & 18.77 & 8.14 & -8.89 & 29.75 \\
\hline Precipitation (WB) & 7,952 & Millimeters (mm) & 1121.264 & 768.62 & 11.27 & 4370.79 \\
\hline \multicolumn{7}{|l|}{ Rich Countries } \\
\hline Real GDP at constant 2011 national prices & 4503 & Million 2011US\$ & 441940.6 & 1230183 & 42.11 & $1.65 \mathrm{e}+07$ \\
\hline Capital stock GDP at constant 2011 national prices & 4503 & Million 2011US\$ & 1461970 & 3999648 & 317.68 & $5.12 \mathrm{e}+07$ \\
\hline Number of persons engaged (Employment) & 4503 & Millions & 8.90 & 17.75 & 0.001 & 148.46 \\
\hline Temperature (BHM) & 3352 & Celsius $\left({ }^{\circ} \mathrm{C}\right)$ & 15.38 & 7.077 & -0.32 & 28.27 \\
\hline Precipitation (BHM) & 3352 & Millimeters (mm) & 990.44 & 689.02 & 5.38 & 4877.74 \\
\hline Temperature (WB) & 4503 & Celsius $\left({ }^{\circ} \mathrm{C}\right)$ & 15.77 & 8.39 & -8.89 & 29.03 \\
\hline Precipitation (WB) & 4503 & Millimeters (mm) & 1070.44 & 789.32 & 11.27 & 4370.79 \\
\hline \multicolumn{7}{|l|}{ Poor Countries } \\
\hline Real GDP at constant 2011 national prices & 3449 & Million 2011US\$ & 168387.1 & 852194.8 & 267.33 & $1.72 \mathrm{e}+07$ \\
\hline Capital stock GDP at constant 2011 national prices & 3449 & Million 2011US\$ & 500373.4 & 2848797 & 405.58 & $6.76 \mathrm{e}+07$ \\
\hline
\end{tabular}




\begin{tabular}{|l|r|l|r|r|r|r|}
\hline Number of persons engaged (Employment) & 3449 & Millions & 21.81 & 84.37 & 0.03 & 798.37 \\
\hline Temperature (BHM) & 2815 & Celsius $\left({ }^{0} \mathrm{C}\right)$ & 22.57 & 5.39 & -2.37 & 29.61 \\
\hline Precipitation (BHM) & 2815 & Millimeters (mm) & 1204.37 & 691.48 & 9.12 & 4008.5 \\
\hline Temperature (WB) & 3449 & Celsius $\left({ }^{0} \mathrm{C}\right)$ & 22.68 & 5.83 & -1.55 & 29.75 \\
\hline Precipitation (WB) & 3449 & Millimeters (mm) & 1187.62 & 735.57 & 18.62 & 3605.38 \\
\hline
\end{tabular}

Note: A country is defined to be poor if its per capita income, adjusted for purchasing-power-parity (PPP), was below the sample median in 1980, which was $2011 \mathrm{US} \$ 5173$.

Number countries are 77 and number of countries are 91 for un-weighted temperature and economic variables. However, Number of countries are153 (poor: 73 and rich: 80 ) for population weighted climatic variables. WB and BHM in parentheses implies that the information on temperature and precipitation are taken from the World Bank and Burke et al. (2015), respectively. 
Table A1.1: Im-Pesaran-Shin panel unit-root test

\begin{tabular}{|l|r|l|r|}
\hline \multicolumn{2}{|l|}{ In Levels } & \multicolumn{2}{l|}{ In First Difference } \\
\hline Variable & Z-t-tilde-bar & Variable & Z-t-tilde-bar \\
\hline Ln(real GDP) & 10.30 & Ln(real GDP) & $-40.56^{* * *}$ \\
\hline $\ln$ (capital stock) & 19.73 & $\ln$ (capital stock) & $-7.70^{* * *}$ \\
\hline $\ln ($ employment) & 18.96 & $\ln ($ employment) & $-35.08^{* * *}$ \\
\hline Temperature (BHM) & $-24.19^{* * *}$ & & \\
\hline Precipitation (BHM) & $-38.26^{* * *}$ & & \\
\hline Temperature (WB) & $-28.87^{* * *}$ & & \\
\hline Precipitation (WB) & $-49.06^{* * *}$ & & \\
\hline
\end{tabular}

Note: Ho: All panels contain unit roots; Ha: Some panels are stationary

${ }^{* * *}$ Significant at the 1 percent level.

Table A1.2: Panel unit root tests for economic variables

\begin{tabular}{|c|c|c|c|c|c|}
\hline & & \multicolumn{2}{|c|}{$\begin{array}{l}\text { (A) Maddala and Wu (1999) } \\
\text { (MW) }\end{array}$} & \multicolumn{2}{|c|}{ (B) Pesaran (2007) (CIPS) } \\
\hline & & without trend & with trend & without trend & with trend \\
\hline Variable & Lags & chi_sq & chi_sq & Zt-bar & Zt-bar \\
\hline \multicolumn{6}{|l|}{ In Levels } \\
\hline \multirow[b]{5}{*}{ Ln(real GDP) } & 0 & $652.02^{* * *}$ & 378.79 & -0.97 & 4.47 \\
\hline & 1 & 333.77 & $660.09^{* * * *}$ & -0.20 & 1.03 \\
\hline & 2 & 372.37 & 371.89 & 0.37 & 3.01 \\
\hline & 3 & 381.04 & 418.05 & 1.28 & 5.59 \\
\hline & 4 & 329.53 & 290.41 & 2.82 & 7.39 \\
\hline \multirow{5}{*}{$\begin{array}{l}\text { Ln(capital } \\
\text { stock) }\end{array}$} & 0 & $1902.24^{* * *}$ & 337.73 & 5.65 & 19.44 \\
\hline & 1 & 314.45 & $400.43^{* * *}$ & 2.01 & 4.26 \\
\hline & 2 & 313.57 & 257.73 & 4.96 & 10.23 \\
\hline & 3 & 297.67 & 315.55 & 5.45 & 9.58 \\
\hline & 4 & 296.29 & 341.88 & 5.69 & 11.85 \\
\hline \multirow[b]{5}{*}{ Ln(employment) } & 0 & $527.19^{* * * *}$ & 361.18 & 13.17 & 4.54 \\
\hline & 1 & 219.62 & $503.26^{* * * *}$ & 11.36 & $-2.49^{* * *}$ \\
\hline & 2 & 189.26 & 362.50 & 12.43 & 0.81 \\
\hline & 3 & 168.26 & 365.86 & 13.07 & 0.76 \\
\hline & 4 & 157.48 & 286.34 & 13.90 & 2.82 \\
\hline \multicolumn{6}{|l|}{ In First Difference } \\
\hline \multirow[b]{5}{*}{$\ln ($ real GDP $)$} & 0 & $4243.57^{* * *}$ & $4029.27^{* * *}$ & $-44.48^{* * *}$ & $-44.21^{* * *}$ \\
\hline & 1 & $2734.53^{* * *}$ & $2501.23^{* * *}$ & $-30.68^{* * *}$ & $-29.63^{* * *}$ \\
\hline & 2 & $1666.09^{* * *}$ & $1495.88^{* * * *}$ & $-19.93^{* * * *}$ & $-18.45^{* * *}$ \\
\hline & 3 & $1260.53^{* * *}$ & $1128.54^{* * *}$ & $-13.57^{* * * *}$ & $-11.81^{* * *}$ \\
\hline & 4 & $912.41^{* * * *}$ & $888.15^{\text {**** }}$ & $-6.91^{* * *}$ & $-5.38^{* * *}$ \\
\hline \multirow[b]{4}{*}{$\ln$ (capital stock) } & 0 & $597.27^{* * * *}$ & $613.73^{* * *}$ & $-8.33^{* * *}$ & $-9.55^{* * *}$ \\
\hline & 1 & $672.79^{* * * *}$ & $666.49^{* * *}$ & $-9.20^{* * *}$ & $-11.39^{* * * *}$ \\
\hline & 2 & $511.63^{* * *}$ & $509.97^{* * * *}$ & $-3.41^{* * * *}$ & $-5.23^{* * *}$ \\
\hline & 3 & $487.22^{* * * *}$ & $436.97^{* * * *}$ & $-2.21^{* *}$ & $-3.81^{* * *}$ \\
\hline
\end{tabular}




\begin{tabular}{|r|r|r|r|r|r|} 
& 4 & $445.53^{* * *}$ & $476.61^{* * *}$ & 0.30 & $-1.67^{* *}$ \\
\hline & 0 & $3835.52^{* * *}$ & $3426.46^{* * *}$ & $-36.90^{* * * *}$ & $-35.15^{* * *}$ \\
\cline { 2 - 6 } & 1 & $2237.52^{* * *}$ & $1915.29^{* * *}$ & $-26.19^{* * *}$ & $-23.31^{* * *}$ \\
\cline { 2 - 6 } & 2 & $1378.30^{* * *}$ & $1094.61^{* * *}$ & $-15.14^{* * *}$ & $-11.36^{* * *}$ \\
\cline { 2 - 6 } $\ln ($ employment $)$ & 3 & $1098.66^{* * *}$ & $853.16^{* * *}$ & $-10.76^{* * * *}$ & $-6.95^{* * *}$ \\
\cline { 2 - 6 } & 4 & $863.85^{* * *}$ & $667.42^{* * * *}$ & $-6.08^{* * * *}$ & $-2.31^{* *}$ \\
\hline
\end{tabular}

Note: Null for MW and CIPS tests: series is I(1). MW test assumes cross-section independence. CIPS test assumes cross-section dependence is in form of a single unobserved common factor.

*** Significant at the 1 percent level.

${ }^{* *}$ Significant at the 5 percent level.

Table 1.3 Panel unit root tests for weather variables

\begin{tabular}{|c|c|c|c|c|c|}
\hline & & \multicolumn{2}{|c|}{ (A) Maddala and Wu (1999) (MW) } & \multicolumn{2}{|c|}{ (B) Pesaran (2007) (CIPS) } \\
\hline & & without trend & with trend & without trend & with trend \\
\hline Variable & Lags & chi_sq & chi_sq & Zt-bar & Zt-bar \\
\hline \multicolumn{6}{|l|}{ In Levels } \\
\hline \multirow{5}{*}{$\begin{array}{l}\text { Temperature } \\
(\mathrm{BHM})\end{array}$} & 0 & $1732.84^{* * * *}$ & $2592.19^{* * *}$ & $-22.85^{\text {*** }}$ & $-33.06^{* * *}$ \\
\hline & 1 & $963.85^{* * *}$ & $1716.64^{* * *}$ & $-12.45^{\text {*** }}$ & $-23.68^{* * * *}$ \\
\hline & 2 & $550.10^{* * *}$ & $909.44^{* * *}$ & $-2.44^{* * * *}$ & $-12.01^{* * *}$ \\
\hline & 3 & $414.62^{* * * *}$ & $695.60^{* * * *}$ & 2.88 & $-4.84^{* * * *}$ \\
\hline & 4 & 272.44 & $484.91^{* * * *}$ & 4.35 & $-3.71^{* * *}$ \\
\hline \multirow{5}{*}{$\begin{array}{l}\text { Precipitation } \\
(\mathrm{BHM})\end{array}$} & 0 & $3807.29^{* * *}$ & $3384.58^{* * *}$ & $-42.42^{* * *}$ & $-40.48^{* * *}$ \\
\hline & 1 & $1874.85^{* * *}$ & $1607.08^{* * * *}$ & $-24.41^{\text {*** }}$ & $-21.75^{* * *}$ \\
\hline & 2 & $1235.28^{* * *}$ & $982.53^{* * *}$ & $-15.31^{* * *}$ & $-11.82^{* * *}$ \\
\hline & 3 & $1018.61^{* * * *}$ & $793.97^{* * *}$ & $-12.01^{* * *}$ & $-8.23^{* * *}$ \\
\hline & 4 & $743.28^{* * *}$ & $564.01^{* * *}$ & $-6.38^{* * * *}$ & $-2.37^{* * *}$ \\
\hline \multirow{5}{*}{$\begin{array}{l}\text { Temperature } \\
\text { (WB) }\end{array}$} & 0 & $2104.22^{* * *}$ & $3452.17^{* * *}$ & $-31.27^{* * *}$ & $-45.06^{* * *}$ \\
\hline & 1 & $1024.45^{* * *}$ & $1951.55^{* * *}$ & $-14.57^{* * *}$ & $-27.73^{* * *}$ \\
\hline & 2 & $528.87^{* * *}$ & $1064.59^{* * *}$ & $-4.93^{* * * *}$ & $-15.38^{* * *}$ \\
\hline & 3 & $381.85^{* *}$ & $844.66^{* * *}$ & -0.89 & $-11.36^{* * *}$ \\
\hline & 4 & 318.06 & $651.34^{* * *}$ & 2.61 & $-5.26^{* * *}$ \\
\hline \multirow{5}{*}{$\begin{array}{l}\text { Precipitation } \\
\text { (WB) }\end{array}$} & 0 & $5786.70^{* * * *}$ & $5309.68^{* * *}$ & $-50.13^{* * *}$ & $-49.13^{* * *}$ \\
\hline & 1 & $2983.76^{* * *}$ & $2707.63^{* * *}$ & $-33.90^{* * *}$ & $-32.29^{* * *}$ \\
\hline & 2 & $1893.09^{* * * *}$ & $1654.45^{* * *}$ & $-22.81^{* * *}$ & $-20.33^{* * *}$ \\
\hline & 3 & $1385.22^{* * * *}$ & $1183.67^{* * *}$ & $-15.50^{* * * *}$ & $-12.74^{* * *}$ \\
\hline & 4 & $1045.54^{* * * *}$ & $910.46^{* * *}$ & $-10.21^{* * * *}$ & $-6.41^{* * *}$ \\
\hline
\end{tabular}

Note: Null for MW and CIPS tests: series is I(1). MW test assumes cross-section independence. CIPS test assumes cross-section dependence is in form of a single unobserved common factor. 
*** Significant at the 1 percent level.

Table A2: Cross-sectional depedence test

\begin{tabular}{|l|l|}
\hline Pesaran's test of cross sectional independence: 54.64 & $\begin{array}{l}\text { Without year dummies, weather } \\
\text { variables (BHM) }\end{array}$ \\
\hline Pesaran's test of cross sectional independence: -0.12 & $\begin{array}{l}\text { With year dummies, weather } \\
\text { variables (BHM) }\end{array}$ \\
\hline Pesaran's test of cross sectional independence: $58.24^{* * * *}$ & $\begin{array}{l}\text { Without year dummies, weather } \\
\text { variables (WB) }\end{array}$ \\
\hline Pesaran's test of cross sectional independence: -0.12 & $\begin{array}{l}\text { With year dummies, weather } \\
\text { variables (WB) }\end{array}$ \\
\hline
\end{tabular}

Note: Ho: Cross-sectional independence; Ha: Cross-sectional dependence

*** Significant at the 1 percent level.

Table A3.1: Pedroni Co-integration tests

\begin{tabular}{|c|c|c|c|c|}
\hline & \multicolumn{2}{|l|}{ Area } & \multicolumn{2}{|l|}{ Population } \\
\hline Test Stats. & Panel & Group & Panel & Group \\
\hline $\mathrm{v}$ & $5.663^{* * *}$ & & $4.643^{* * * *}$ & \\
\hline rho & $-36.63^{* * *}$ & $-27.95^{* * * *}$ & $-24.72^{* * * *}$ & $-18.38^{* * *}$ \\
\hline$t$ & $-48.49^{* * * *}$ & $-53.93^{* * *}$ & $-37.7^{* * *}$ & $-42.73^{* * *}$ \\
\hline adf & $-38.73^{* * *}$ & $-36.97^{* * * *}$ & $-29.88^{* * * *}$ & $-29.56^{* * * *}$ \\
\hline
\end{tabular}

All test statistics are distributed $\mathrm{N}(0,1)$, under a null of no cointegration, and diverge to negative infinity (save for panel $\mathrm{v}$ ).

${ }^{* * *}$ Significant at the 1 percent level.

Table A3.2: Westerlund ECM panel co-integration tests

\begin{tabular}{|c|c|c|c|c|}
\hline & \multicolumn{2}{|l|}{ Area } & \multicolumn{2}{|l|}{ Population } \\
\hline Statistic & Value & Z-value & Value & $\mathrm{Z}$-value \\
\hline $\mathrm{Gt}$ & $-3.81^{* * *}$ & -35.36 & $-3.61^{* * * *}$ & -31.26 \\
\hline $\mathrm{Ga}$ & $-27.44^{* * * *}$ & -67.36 & $-23.08^{* * * *}$ & -52.42 \\
\hline $\mathrm{Pt}$ & $-63.62^{* * *}$ & -48.84 & $-57.54^{* * * *}$ & -43.89 \\
\hline $\mathrm{Pa}$ & $-32.96^{* * *}$ & -142.95 & $-27.84^{* * *}$ & -114.56 \\
\hline
\end{tabular}

Results for H0: no co-integration

${ }^{* * *}$ Significant at the 1 percent level.

Table A4: Parameter estimates of stochastic frontier

\begin{tabular}{|l|r|r|r|r|}
\hline \multirow{2}{*}{} & \multicolumn{2}{|l|}{$\begin{array}{l}\text { Weather variables are taken } \\
\text { from Burke et al. (2015) }\end{array}$} & $\begin{array}{l}\text { Weather variables are } \\
\text { taken from the World } \\
\text { Bank }\end{array}$ \\
\cline { 2 - 5 } & \multicolumn{1}{|l|}{$(1)$} & $(2)$ & $(3)$ & $(4)$ \\
\hline Frontier & $0.570^{* * *}$ & $0.573^{* * *}$ & $0.562^{* * *}$ & $0.570^{* * *}$ \\
\hline$\Delta \ln ($ rkna $)$ & $(27.6)$ & $(27.84)$ & $(31.31)$ & $(31.65)$ \\
\hline & $0.286^{* * *}$ & $0.292^{* * *}$ & $0.295^{* * *}$ & $0.302^{* * *}$ \\
\hline$\Delta \ln (\mathrm{emp})$ & & &
\end{tabular}




\begin{tabular}{|c|c|c|c|c|}
\hline & $(13.01)$ & $(13.28)$ & $(14.55)$ & $(14.87)$ \\
\hline Year fixed effects & Yes & Yes & Yes & Yes \\
\hline \multicolumn{5}{|l|}{$\Delta \mu$} \\
\hline \multirow[t]{2}{*}{ Temperature } & $0.946^{* * *}$ & $0.914^{* * *}$ & $0.635^{* *}$ & $0.612^{* * *}$ \\
\hline & (3.5) & $(2.55)$ & $(2.41)$ & $(2.82)$ \\
\hline \multirow[t]{2}{*}{ Precipitation } & $0.005^{* * *}$ & 0.003 & $0.006^{* * *}$ & $0.004^{* * *}$ \\
\hline & $(4.29)$ & $(1.55)$ & $(4.16)$ & $(4.21)$ \\
\hline \multirow[t]{2}{*}{ Poor $\times$ Temperature } & & -0.178 & & 0.165 \\
\hline & & $(-1.17)$ & & $(0.78)$ \\
\hline \multirow[t]{2}{*}{ Poor $\times$ Precipitation } & & 0.002 & & -0.005 \\
\hline & & $(1.17)$ & & $(-1.35)$ \\
\hline \multirow[t]{2}{*}{ Constant } & $-47.10^{* * * *}$ & -35.86 & $-42.71^{* * *}$ & $-32.11^{* * *}$ \\
\hline & $(-4.22)$ & $(-1.6)$ & $(-4.21)$ & $(-4.4)$ \\
\hline \multicolumn{5}{|l|}{$\Delta \sigma_{u}$} \\
\hline \multirow[t]{2}{*}{ Temperature } & $-0.032^{* * * *}$ & $-0.036^{* * *}$ & $-0.019^{* *}$ & $-0.020^{* *}$ \\
\hline & $(-4.88)$ & $(-3.59)$ & $(-2.32)$ & $(-2.18)$ \\
\hline \multirow[t]{2}{*}{ Precipitation } & $-0.0005^{\text {*** }}$ & $-0.001^{* * *}$ & $-0.0005^{* * *}$ & $-0.001^{* * *}$ \\
\hline & $(-13.86)$ & $(-12.31)$ & $(-15.13)$ & $(-17.29)$ \\
\hline \multirow[t]{2}{*}{ Poor $\times$ Temperature } & & $-0.017^{*}$ & & $-0.037^{* *}$ \\
\hline & & $(-1.71)$ & & $(-2.43)$ \\
\hline \multirow[t]{2}{*}{ Poor $\times$ Precipitation } & & $0.0004^{* * *}$ & & $0.001^{* * * *}$ \\
\hline & & (3.5) & & $(3.3)$ \\
\hline \multirow[t]{2}{*}{ Constant } & $0.729^{* * *}$ & 0.534 & $0.483^{*}$ & 0.242 \\
\hline & $(2.84)$ & $(0.83)$ & (1.86) & $(0.95)$ \\
\hline \multicolumn{5}{|l|}{$\Delta \sigma_{v}$} \\
\hline \multirow[t]{2}{*}{ Constant } & $-6.296^{* * * *}$ & $-6.286^{* * *}$ & $-6.251^{* * *}$ & $-6.244^{* * *}$ \\
\hline & $(-267.62)$ & $(-266.78)$ & $(-303.16)$ & $(-302.73)$ \\
\hline \multirow[t]{2}{*}{$\mathrm{E}\left(\Delta \sigma_{u}\right)$} & $0.840^{* * * *}$ & $0.685^{* * * *}$ & $0.824^{* * *}$ & $0.688^{* * *}$ \\
\hline & $(89.65)$ & $(78.86)$ & (106.09) & (99.27) \\
\hline \multirow[t]{2}{*}{$\Delta \sigma_{v}$} & $0.043^{* * *}$ & $0.043^{* * *}$ & $0.044^{* * * *}$ & $0.044^{* * * *}$ \\
\hline & $(85.01)$ & $(84.87)$ & $(97.0)$ & (96.96) \\
\hline Log likelihood & 9296.98 & 9330.03 & 11849.54 & 11882.84 \\
\hline
\end{tabular}




\begin{tabular}{|l|r|r|r|r|}
\hline Number of obs & 6112 & 6112 & 7784 & 7784 \\
\hline Number of Countries & 153 & 153 & 168 & 168 \\
\hline
\end{tabular}

Note: Dependent variable is $\Delta \ln$ (rgdpna) and independent variables in frontier are $\Delta \ln (\mathrm{rkna})$ and $\Delta \ln (\mathrm{emp})$. In the equations of $\mathrm{Mu}$ and Usigma the indepdeent variables are temperature and precipitation in levels. Figures in parentheses are t-statistics. A country is defined to be poor if its per capita income, adjusted for purchasingpower-parity (PPP), was below the sample median in 1980, which was 2011US\$ 5173. Sample includes all the countries for which the complete panel data on both climate and economic variables is available for at least eighteen years.

${ }^{* * * *}$ Significant at the 1 percent level.

${ }^{* *}$ Significant at the 5 percent level.

${ }^{*}$ Significant at the 10 percent level 
Table A5: Parameter estimates of stochastic frontier (for different samples)

\begin{tabular}{|c|c|c|c|c|c|c|c|}
\hline & $\begin{array}{l}\text { Excluding } \\
\text { SSA (BHM) }\end{array}$ & $\begin{array}{l}\text { Excluding } \\
\text { SSA (WB) }\end{array}$ & $\begin{array}{l}\text { Only SSA } \\
(\mathrm{BHM})\end{array}$ & $\begin{array}{l}\text { Only SSA } \\
\text { (WB) }\end{array}$ & $\begin{array}{l}\text { Sample } 1970 \\
\text { to } 2014(\mathrm{WB})\end{array}$ & $\begin{array}{l}\text { Sample 1990- } \\
2014 \text { (WB) }\end{array}$ & $\begin{array}{l}\text { Sample 1960- } \\
2010(\mathrm{WB})\end{array}$ \\
\hline & (1) & (2) & (3) & (4) & (5) & (6) & (7) \\
\hline \multicolumn{8}{|l|}{ Frontier } \\
\hline \multirow[t]{2}{*}{$\Delta \ln (\mathrm{rkna})$} & $0.539^{* * *}$ & $0.575^{* * *}$ & $0.562^{* * * *}$ & $0.521^{* * *}$ & $0.548^{* * *}$ & $0.523^{* * * *}$ & $0.587^{* * * *}$ \\
\hline & $(20.65)$ & $(25.62)$ & $(16.21)$ & $(16.55)$ & (29.14) & (22.86) & $(29.07)$ \\
\hline \multirow[t]{2}{*}{$\Delta \ln (\mathrm{emp})$} & $0.314^{* * *}$ & $0.319^{* * * *}$ & $0.164^{* * *}$ & $0.158^{* * * *}$ & $0.285^{* * *}$ & $0.238^{* * * *}$ & $0.280^{* * * *}$ \\
\hline & (12.68) & $(14.01)$ & $(3.75)$ & $(3.72)$ & $(13.95)$ & $(9.93)$ & $(13.0)$ \\
\hline Year fixed effects & Yes & Yes & Yes & Yes & Yes & Yes & Yes \\
\hline \multicolumn{8}{|l|}{$\Delta \mu$} \\
\hline \multirow[t]{2}{*}{ Temperature } & $0.692^{* * * *}$ & $0.629^{* *}$ & 0.164 & 1.325 & $0.706^{* *}$ & $0.993^{*}$ & $0.767^{* * *}$ \\
\hline & $(3.25)$ & $(2.58)$ & $(0.22)$ & (1.41) & $(2.43)$ & $(1.85)$ & $(2.83)$ \\
\hline \multirow[t]{2}{*}{ Precipitation } & $0.004^{* * * *}$ & $0.004^{* * * *}$ & $0.008^{*}$ & $-0.016^{* * *}$ & $0.006^{* * *}$ & $0.007^{* *}$ & $0.006^{* * *}$ \\
\hline & (3.97) & $(4.24)$ & $(1.88)$ & $(-2.1)$ & $(4.04)$ & $(2.43)$ & $(4.98)$ \\
\hline \multirow[t]{2}{*}{ Constant } & $-36.792^{* * *}$ & $-33.870^{* * *}$ & -31.213 & -40.785 & $-46.18^{* * *}$ & $-56.514^{* *}$ & $-45.51^{* * * *}$ \\
\hline & $(-4.09)$ & $(-3.9)$ & $(-1.31)$ & (1.44) & $(-4.05)$ & $(-2.43)$ & $(-4.87)$ \\
\hline \multicolumn{8}{|l|}{$\Delta \sigma_{u}$} \\
\hline \multirow[t]{2}{*}{ Temperature } & $-0.025^{* * *}$ & $-0.024^{* * * *}$ & -0.0001 & $-0.071^{* *}$ & $-0.022^{* * *}$ & $-0.040^{* * *}$ & $-0.026^{* * * *}$ \\
\hline & $(-3.5)$ & $(-2.73)$ & (1.10) & $(-2.17)$ & $(-2.64)$ & $(-4.05)$ & $(-3.15)$ \\
\hline Precipitation & -0.001 & -0.001 & -0.0002 & 0.001 & -0.0005 & -0.0004 & -0.0005 \\
\hline
\end{tabular}




\begin{tabular}{|c|c|c|c|c|c|c|c|}
\hline & $(-15.74)$ & $(-19.23)$ & $(-1.28)$ & (7.76) & $(-12.93)$ & $(-6.3)$ & $(-14.21)$ \\
\hline \multirow[t]{2}{*}{ Constant } & $0.535^{* *}$ & 0.320 & -0.690 & 0.006 & $0.604^{* *}$ & $0.98^{* *}$ & $0.645^{* * * *}$ \\
\hline & $(2.04)$ & (1.13) & $(-0.61)$ & $(0.01)$ & $(2.23)$ & $(2.24)$ & $(2.76)$ \\
\hline \multicolumn{8}{|l|}{$\Delta \sigma_{v}$} \\
\hline \multirow[t]{2}{*}{ Constant } & $-6.46^{* * *}$ & $-6.34^{* * *}$ & $-5.98^{* * *}$ & $-6.05^{* * *}$ & $-6.34^{* * *}$ & $-6.29^{* * *}$ & $-6.17^{* * *}$ \\
\hline & $(-233.39)$ & $(-267.87)$ & $(-135.06)$ & $(-146.4)$ & $(-274.72)$ & $(-225.09)$ & $(-277.25)$ \\
\hline \multirow[t]{2}{*}{$\mathrm{E}\left(\Delta \sigma_{u}\right)$} & $0.772^{* * *}$ & $0.698^{* * * *}$ & $0.650^{* * * *}$ & $0.799^{* * *}$ & $0.867^{* * * *}$ & $0.931^{* * * *}$ & $0.843^{* * *}$ \\
\hline & (66.95) & $(70.15)$ & $(262.88)$ & $(32.70)$ & $(97.42)$ & (63.05) & (90.63) \\
\hline \multirow[t]{2}{*}{$\Delta \sigma_{v}$} & $0.040^{* * *}$ & $0.042^{* * *}$ & $0.050^{* * *}$ & $0.049^{* * *}$ & $0.042^{* * * *}$ & $0.043^{* * *}$ & $0.046^{* * *}$ \\
\hline & $(72.26)$ & $(84.51)$ & (45.17) & (48.44) & $(86.72)$ & (71.51) & $(89.85)$ \\
\hline Log likelihood & 7047.28 & 9191.66 & 2403.43 & 2807.46 & 9891.83 & 6127.72 & 9806.23 \\
\hline Number of obs & 4450 & 5870 & 1662 & 1914 & 6415 & 4002 & 6609 \\
\hline $\begin{array}{l}\text { Number of } \\
\text { Countries }\end{array}$ & 110 & 124 & 43 & 44 & 168 & 168 & 168 \\
\hline
\end{tabular}

Note: SSA: Sub Saharan Africa. Dependent variable is $\Delta \ln ($ rgdpna) and independent variables in frontier are $\Delta \ln (\mathrm{rkna})$ and $\Delta \ln (\mathrm{emp})$. In the equations of Mu and Usigma the indepdeent variables are temperature and precipitation in levels. Figures in parentheses are t-statistics. Sample includes all the countries for which the complete panel data on both climate and economic variables is available for at least eighteen years.

*** Significant at the 1 percent level.

** Significant at the 5 percent level.

* Significant at the 10 percent level. 
Table A6: Average annual marginal effects of temperature on mean and variance of production efficiency growth at the country level (percentage points)

\begin{tabular}{|c|c|c|c|c|c|c|c|}
\hline Country & $\begin{array}{l}\text { Country } \\
\text { Code }\end{array}$ & $\begin{array}{l}\text { Average } \\
\text { Annual } \\
\text { Temperat } \\
\text { ure }\left({ }^{\circ} \mathrm{C}\right) \\
(\mathrm{BHM})\end{array}$ & $\begin{array}{l}\partial E(\Delta \mu) / \partial T \\
(\mathrm{BHM})\end{array}$ & $\begin{array}{l}\partial \Delta \sigma_{u}^{2} / \partial T \\
(\mathrm{BHM})\end{array}$ & $\begin{array}{l}\text { Averag } \\
\mathrm{e} \\
\text { Annual } \\
\text { Temper } \\
\text { ature } \\
\left({ }^{\circ} \mathrm{C}\right) \\
(\mathrm{WB})\end{array}$ & $\begin{array}{l}\partial E(\Delta \mu) / \partial T \\
(\mathrm{WB})\end{array}$ & $\begin{array}{l}\partial \Delta \sigma_{u}^{2} / \partial T \\
(\mathrm{WB})\end{array}$ \\
\hline Iceland & ISL & 1.44 & -0.0207 & -0.0012 & 1.90 & 0.0063 & 0.0003 \\
\hline Finland & FIN & 3.42 & -0.0209 & -0.0014 & 1.67 & 0.0035 & 0.0002 \\
\hline $\begin{array}{l}\text { Russian } \\
\text { Federation }\end{array}$ & RUS & 4.32 & -0.0191 & -0.0013 & -5.22 & -0.0052 & -0.0003 \\
\hline Norway & NOR & 4.65 & -0.0107 & -0.0006 & 1.13 & 0.0054 & 0.0002 \\
\hline Sweden & SWE & 5.65 & -0.0137 & -0.0009 & 1.83 & 0.0044 & 0.0002 \\
\hline Estonia & EST & 5.65 & -0.0132 & -0.0008 & 6.18 & 0.0108 & 0.0006 \\
\hline Canada & CAN & 5.65 & -0.0096 & -0.0005 & -6.56 & -0.0063 & -0.0004 \\
\hline Kazakhstan & KAZ & 6.34 & -0.0166 & -0.0012 & 6.69 & 0.0096 & 0.0007 \\
\hline Latvia & LVA & 6.54 & -0.0102 & -0.0006 & 6.71 & 0.0117 & 0.0006 \\
\hline Belarus & BLR & 6.76 & -0.0098 & -0.0006 & 7.39 & 0.0126 & 0.0007 \\
\hline Lithuania & LTU & 6.93 & -0.0089 & -0.0006 & 7.24 & 0.0125 & 0.0007 \\
\hline Switzerland & $\mathrm{CHE}$ & 7.29 & -0.0011 & -0.0001 & 6.34 & 0.0134 & 0.0005 \\
\hline Austria & AUT & 7.70 & -0.0029 & -0.0002 & 6.52 & 0.0129 & 0.0006 \\
\hline Denmark & DNK & 7.85 & -0.0066 & -0.0004 & 8.09 & 0.0142 & 0.0008 \\
\hline $\begin{array}{l}\text { Czech } \\
\text { Republic }\end{array}$ & CZE & 7.96 & -0.0056 & -0.0004 & 8.70 & 0.0152 & 0.0008 \\
\hline Poland & POL & 8.05 & -0.0059 & -0.0004 & 8.24 & 0.0141 & 0.0008 \\
\hline Slovakia & SVK & 8.42 & -0.0031 & -0.0002 & 8.38 & 0.0148 & 0.0008 \\
\hline Slovenia & SVN & 8.56 & 0.0023 & 0.0001 & 9.66 & 0.0185 & 0.0008 \\
\hline Ukraine & UKR & 8.57 & -0.0043 & -0.0003 & 9.03 & 0.0154 & 0.0009 \\
\hline Germany & DEU & 8.76 & -0.0011 & -0.0001 & 8.86 & 0.0156 & 0.0009 \\
\hline Ireland & IRL & 8.82 & 0.0013 & 0.0001 & 9.33 & 0.0175 & 0.0008 \\
\hline Luxembou & LUX & 9.02 & -0.0003 & 0.0000 & 9.32 & 0.0171 & 0.0008 \\
\hline $\begin{array}{l}\text { United } \\
\text { Kingdom } \\
\end{array}$ & GBR & 9.40 & 0.0015 & 0.0001 & 8.65 & 0.0164 & 0.0007 \\
\hline Chile & $\mathrm{CHL}$ & 9.86 & 0.0015 & 0.0001 & 8.34 & 0.0143 & 0.0008 \\
\hline Netherlands & NLD & 9.90 & 0.0032 & 0.0002 & 9.69 & 0.0174 & 0.0009 \\
\hline Belgium & BEL & 9.95 & 0.0037 & 0.0002 & 9.89 & 0.0180 & 0.0009 \\
\hline $\begin{array}{l}\text { TFYR of } \\
\text { Macedoni }\end{array}$ & MKD & 9.96 & 0.0021 & 0.0001 & 10.50 & 0.0186 & 0.0011 \\
\hline Bulgaria & BGR & 10.08 & 0.0022 & 0.0001 & 10.87 & 0.0193 & 0.0011 \\
\hline Serbia & SRB & 10.13 & 0.0030 & 0.0002 & 11.05 & 0.0201 & 0.0011 \\
\hline Hungary & HUN & 10.27 & 0.0027 & 0.0002 & 10.43 & 0.0184 & 0.0011 \\
\hline France & FRA & 10.90 & 0.0074 & 0.0004 & 11.10 & 0.0205 & 0.0011 \\
\hline Georgia & GEO & 11.30 & 0.0103 & 0.0005 & 7.05 & 0.0131 & 0.0006 \\
\hline $\begin{array}{l}\text { Republic of } \\
\text { Korea }\end{array}$ & KOR & 11.51 & 0.0129 & 0.0006 & 11.00 & 0.0212 & 0.0009 \\
\hline Croatia & HRV & 11.89 & 0.0129 & 0.0007 & 11.39 & 0.0216 & 0.0010 \\
\hline
\end{tabular}




\begin{tabular}{|c|c|c|c|c|c|c|c|}
\hline Turkey & TUR & 12.31 & 0.0126 & 0.0008 & 11.31 & 0.0201 & 0.0012 \\
\hline New Zealand & NZL & 12.70 & 0.0176 & 0.0008 & 9.93 & 0.0195 & 0.0007 \\
\hline Italy & ITA & 12.84 & 0.0175 & 0.0009 & 12.03 & 0.0227 & 0.0012 \\
\hline Azerbaijan & AZE & 12.97 & 0.0145 & 0.0010 & 11.71 & 0.0207 & 0.0013 \\
\hline United States & USA & 13.43 & 0.0203 & 0.0011 & 7.10 & 0.0122 & 0.0007 \\
\hline Lebanon & LBN & 13.83 & 0.0227 & 0.0012 & 16.11 & 0.0330 & 0.0021 \\
\hline Japan & JPN & 13.86 & 0.0238 & 0.0009 & 10.82 & 0.0212 & 0.0008 \\
\hline Spain & ESP & 14.48 & 0.0250 & 0.0016 & 13.35 & 0.0252 & 0.0015 \\
\hline Greece & GRC & 14.92 & 0.0277 & 0.0017 & 14.01 & 0.0271 & 0.0016 \\
\hline $\begin{array}{l}\text { Iran (Islamic } \\
\text { Republic of) }\end{array}$ & IRN & 15.07 & 0.0273 & 0.0020 & 17.28 & 0.0362 & 0.0027 \\
\hline Portugal & PRT & 15.10 & 0.0298 & 0.0016 & 14.99 & 0.0302 & 0.0016 \\
\hline Peru & PER & 15.36 & 0.0308 & 0.0019 & 19.49 & 0.0490 & 0.0021 \\
\hline Turkmenistan & TKM & 15.81 & 0.0317 & 0.0026 & 15.97 & 0.0315 & 0.0024 \\
\hline Australia & AUS & 16.54 & 0.0395 & 0.0022 & 21.62 & 0.0558 & 0.0039 \\
\hline Algeria & DZA & 16.85 & 0.0417 & 0.0029 & 22.98 & 0.0621 & 0.0053 \\
\hline Argentina & ARG & 17.23 & 0.0449 & 0.0025 & 14.37 & 0.0278 & 0.0017 \\
\hline South Africa & ZAF & 17.44 & 0.0468 & 0.0029 & 17.76 & 0.0386 & 0.0026 \\
\hline Jordan & JOR & 17.55 & 0.0475 & 0.0038 & 18.83 & 0.0418 & 0.0033 \\
\hline Uruguay & URY & 17.96 & 0.0510 & 0.0027 & 17.74 & 0.0403 & 0.0019 \\
\hline Mexico & MEX & 18.71 & 0.0583 & 0.0033 & 20.78 & 0.0523 & 0.0032 \\
\hline Cyprus & CYP & 18.72 & 0.0595 & 0.0044 & 18.98 & 0.0434 & 0.0029 \\
\hline Ecuador & ECU & 19.34 & 0.0641 & 0.0031 & 21.40 & 0.0665 & 0.0025 \\
\hline Israel & ISR & 20.15 & 0.0770 & 0.0060 & 19.70 & 0.0459 & 0.0035 \\
\hline Colombia & $\mathrm{COL}$ & 20.52 & 0.0775 & 0.0032 & 24.45 & 0.1245 & 0.0047 \\
\hline Namibia & NAM & 21.48 & 0.0971 & 0.0079 & 20.59 & 0.0499 & 0.0038 \\
\hline Angola & AGO & 21.92 & 0.1016 & 0.0061 & 21.74 & 0.0584 & 0.0033 \\
\hline Guatemala & GTM & 21.92 & 0.1023 & 0.0041 & 23.51 & 0.1057 & 0.0038 \\
\hline Iraq & IRQ & 22.01 & 0.1075 & 0.0093 & 21.93 & 0.0566 & 0.0045 \\
\hline Brazil & BRA & 22.02 & 0.1025 & 0.0049 & 25.09 & 0.0956 & 0.0045 \\
\hline Paraguay & PRY & 22.03 & 0.1028 & 0.0051 & 23.45 & 0.0706 & 0.0039 \\
\hline Costa Rica & CRI & 22.13 & 0.1480 & 0.0035 & 24.69 & 0.1849 & 0.0071 \\
\hline Jamaica & JAM & 24.86 & 0.1935 & 0.0093 & 25.07 & 0.1211 & 0.0053 \\
\hline $\begin{array}{l}\text { Dominican } \\
\text { Republic }\end{array}$ & DOM & 25.04 & 0.1892 & 0.0106 & 24.02 & 0.0791 & 0.0040 \\
\hline Gabon & GAB & 25.15 & 0.2050 & 0.0103 & 25.13 & 0.0982 & 0.0046 \\
\hline $\begin{array}{l}\text { Venezuela } \\
\text { (Bolivia) }\end{array}$ & VEN & 25.25 & 0.1913 & 0.0126 & 25.50 & 0.1088 & 0.0049 \\
\hline Bahamas & BHS & 25.41 & 0.1986 & 0.0130 & 25.18 & 0.0876 & 0.0048 \\
\hline Panama & PAN & 25.42 & 0.3051 & 0.0128 & 25.31 & 0.1448 & 0.0058 \\
\hline $\begin{array}{l}\text { Trinidad and } \\
\text { Tobago }\end{array}$ & TTO & 25.50 & 0.2206 & 0.0118 & 26.24 & 0.1076 & 0.0056 \\
\hline Kuwait & KWT & 25.57 & 0.2003 & 0.0203 & 25.64 & 0.0805 & 0.0070 \\
\hline Saudi Arabia & SAU & 25.74 & 0.2066 & 0.0211 & 25.04 & 0.0756 & 0.0067 \\
\hline Malaysia & MYS & 25.96 & 0.3217 & 0.0148 & 25.41 & 0.2141 & 0.0088 \\
\hline Oman & OMN & 26.08 & 0.2181 & 0.0225 & 25.79 & 0.0813 & 0.0072 \\
\hline
\end{tabular}




\begin{tabular}{|c|c|c|c|c|c|c|c|}
\hline Qatar & QAT & 26.80 & 0.2507 & 0.0272 & 27.48 & 0.0959 & 0.0088 \\
\hline Suriname & SUR & 26.91 & 0.3567 & 0.0201 & 25.87 & 0.1369 & 0.0059 \\
\hline $\begin{array}{l}\text { United Arab } \\
\text { Emirates }\end{array}$ & ARE & 26.92 & 0.2560 & 0.0273 & 27.25 & 0.0937 & 0.0086 \\
\hline $\begin{array}{l}\text { Brunei } \\
\text { Darussalam }\end{array}$ & BRN & 27.13 & 1.7561 & 0.1730 & 25.63 & 0.9525 & 0.0904 \\
\hline Montenegro & MNE & & & & 9.52 & 0.0179 & 0.0008 \\
\hline Malta & MLT & & & & 18.85 & 0.0428 & 0.0029 \\
\hline Bermuda & BMU & & & & 21.81 & 0.0621 & 0.0029 \\
\hline $\begin{array}{l}\text { China, Macao } \\
\text { SAR }\end{array}$ & MAC & & & & 23.08 & 0.0812 & 0.0032 \\
\hline Anguilla & AIA & & & & 25.66 & 0.1030 & 0.0051 \\
\hline Barbados & $\mathrm{BRB}$ & & & & 26.38 & 0.1424 & 0.0066 \\
\hline Seychelles & SYC & & & & 27.30 & 0.1269 & 0.0067 \\
\hline Singapore & SGP & & & & 27.34 & 0.2057 & 0.0099 \\
\hline Bahrain & BHR & & & & 27.37 & 0.0950 & 0.0087 \\
\hline $\begin{array}{l}\text { Cayman } \\
\text { Islands }\end{array}$ & CYM & & & & 27.55 & 0.1163 & 0.0069 \\
\hline Aruba & $\mathrm{ABW}$ & & & & 28.34 & 0.1164 & 0.0083 \\
\hline \multicolumn{2}{|l|}{ Rich Countries } & 14.98 & 0.0828 & 0.0062 & 15.86 & 0.0616 & $\mathbf{0 . 0 0 3 8}$ \\
\hline Mongolia & MNG & -0.80 & -0.0469 & -0.0044 & 0.28 & -0.0035 & -0.0003 \\
\hline Kyrgyzstan & KGZ & 6.93 & -0.0168 & -0.0012 & 3.06 & 0.0012 & 0.0001 \\
\hline Armenia & ARM & 8.37 & -0.0110 & -0.0008 & 7.86 & 0.0099 & 0.0006 \\
\hline $\begin{array}{l}\text { Bosnia and } \\
\text { Herzegovina }\end{array}$ & $\mathrm{BIH}$ & 9.65 & 0.0073 & 0.0004 & 10.42 & 0.0132 & 0.0009 \\
\hline $\begin{array}{l}\text { Republic of } \\
\text { Moldova }\end{array}$ & MDA & 9.72 & -0.0049 & -0.0003 & 10.33 & 0.0148 & 0.0009 \\
\hline Lesotho & LSO & 11.68 & 0.0057 & 0.0003 & 13.26 & 0.0202 & 0.0012 \\
\hline Tajikistan & TJK & 11.97 & 0.0014 & 0.0001 & 3.96 & 0.0025 & 0.0002 \\
\hline Bhutan & BTN & 12.75 & 0.1055 & 0.0055 & 11.86 & 0.0135 & 0.0009 \\
\hline Albania & ALB & 13.25 & 0.0218 & 0.0012 & 11.69 & 0.0162 & 0.0010 \\
\hline China & $\mathrm{CHN}$ & 14.07 & 0.0203 & 0.0011 & 6.54 & 0.0072 & 0.0005 \\
\hline Uzbekistan & UZB & 14.27 & 0.0064 & 0.0004 & 13.09 & 0.0215 & 0.0012 \\
\hline Morocco & MAR & 16.76 & 0.0182 & 0.0010 & 17.55 & 0.0325 & 0.0017 \\
\hline $\begin{array}{l}\text { Syrian Arab } \\
\text { Repu }\end{array}$ & SYR & 17.41 & 0.0199 & 0.0011 & 18.01 & 0.0341 & 0.0018 \\
\hline $\begin{array}{l}\text { Bolivia } \\
\text { (Plurinational } \\
\text { State of) }\end{array}$ & $\mathrm{BOL}$ & 17.41 & 0.0350 & 0.0019 & 20.88 & 0.0402 & 0.0021 \\
\hline Tunisia & TUN & 18.74 & 0.0253 & 0.0014 & 19.82 & 0.0402 & 0.0020 \\
\hline Ethiopia & ETH & 19.19 & 0.0477 & 0.0025 & 22.68 & 0.0490 & 0.0025 \\
\hline Kenya & KEN & 19.95 & 0.0570 & 0.0029 & 24.65 & 0.0603 & 0.0030 \\
\hline Swaziland & SWZ & 20.10 & 0.0417 & 0.0022 & 20.32 & 0.0394 & 0.0021 \\
\hline Rwanda & RWA & 20.28 & 0.0545 & 0.0028 & 19.77 & 0.0359 & 0.0020 \\
\hline Zimbabwe & ZWE & 20.46 & 0.0401 & 0.0021 & 21.69 & 0.0457 & 0.0023 \\
\hline Burundi & BDI & 20.56 & 0.0553 & 0.0028 & 20.68 & 0.0389 & 0.0021 \\
\hline Madagascar & MDG & 20.56 & 0.0773 & 0.0039 & 22.80 & 0.0461 & 0.0025 \\
\hline Nepal & NPL & 20.77 & 0.0771 & 0.0039 & 12.64 & 0.0172 & 0.0011 \\
\hline Cabo Verde & $\mathrm{CPV}$ & 21.07 & 0.0458 & 0.0024 & 23.01 & 0.0536 & 0.0027 \\
\hline
\end{tabular}




\begin{tabular}{|c|c|c|c|c|c|c|c|}
\hline Zambia & ZMB & 21.18 & 0.0558 & 0.0029 & 21.84 & 0.0444 & 0.0023 \\
\hline Botswana & BWA & 21.18 & 0.0364 & 0.0019 & 22.18 & 0.0494 & 0.0025 \\
\hline Egypt & EGY & 21.33 & 0.0271 & 0.0015 & 22.52 & 0.0533 & 0.0026 \\
\hline Malawi & MWI & 22.13 & 0.0651 & 0.0033 & 22.06 & 0.0449 & 0.0023 \\
\hline Uganda & UGA & 22.18 & 0.0731 & 0.0037 & 22.93 & 0.0478 & 0.0025 \\
\hline $\begin{array}{l}\text { U.R. of } \\
\text { Tanzania }\end{array}$ & TZA & 22.26 & 0.0642 & 0.0033 & 22.60 & 0.0475 & 0.0025 \\
\hline El Salvador & SLV & 22.78 & 0.1127 & 0.0059 & 24.22 & 0.0505 & 0.0027 \\
\hline Pakistan & PAK & 22.99 & 0.0455 & 0.0024 & 20.15 & 0.0412 & 0.0021 \\
\hline Yemen & YEM & 23.14 & 0.0419 & 0.0022 & 23.86 & 0.0597 & 0.0029 \\
\hline Fiji & FJI & 23.80 & 0.4339 & 0.0358 & 24.25 & 0.0456 & 0.0026 \\
\hline $\begin{array}{l}\text { Lao People's } \\
\text { DR }\end{array}$ & LAO & 23.89 & 0.1313 & 0.0069 & 23.72 & 0.0478 & 0.0026 \\
\hline Mozambique & $\mathrm{MOZ}$ & 24.15 & 0.0773 & 0.0039 & 23.86 & 0.0536 & 0.0028 \\
\hline Mauritius & MUS & 24.18 & 0.1363 & 0.0077 & 23.48 & 0.0468 & 0.0026 \\
\hline Cameroon & CMR & 24.22 & 0.1375 & 0.0073 & 24.72 & 0.0539 & 0.0029 \\
\hline Honduras & HND & 24.41 & 0.1125 & 0.0058 & 23.80 & 0.0475 & 0.0026 \\
\hline $\begin{array}{l}\text { Equatorial } \\
\text { Guinea }\end{array}$ & GNQ & 24.53 & 0.1784 & 0.0099 & 24.78 & 0.0504 & 0.0028 \\
\hline Viet Nam & VNM & 24.76 & 0.1429 & 0.0077 & 24.33 & 0.0504 & 0.0027 \\
\hline Congo & $\mathrm{COG}$ & 25.02 & 0.1205 & 0.0063 & 24.74 & 0.0539 & 0.0029 \\
\hline $\begin{array}{l}\text { Central } \\
\text { African } \\
\end{array}$ & $\mathrm{CAF}$ & 25.05 & 0.1132 & 0.0059 & 25.14 & 0.0581 & 0.0030 \\
\hline Indonesia & IDN & 25.32 & 0.2716 & 0.0169 & 25.93 & 0.0517 & 0.0030 \\
\hline Comoros & $\mathrm{COM}$ & 25.33 & 0.2726 & 0.0174 & 25.61 & 0.0583 & 0.0031 \\
\hline Guinea & GIN & 25.33 & 0.1900 & 0.0107 & 26.05 & 0.0609 & 0.0032 \\
\hline India & IND & 25.58 & 0.1043 & 0.0054 & 24.27 & 0.0554 & 0.0029 \\
\hline Bangladesh & BGD & 25.63 & 0.2181 & 0.0128 & 25.18 & 0.0515 & 0.0029 \\
\hline $\begin{array}{l}\text { Sao Tome and } \\
\text { Principe }\end{array}$ & STP & 25.83 & 0.1562 & 0.0086 & 23.86 & 0.0466 & 0.0026 \\
\hline Philippines & PHL & 25.90 & 0.3448 & 0.0234 & 25.61 & 0.0529 & 0.0030 \\
\hline Liberia & LBR & 25.94 & 0.4188 & 0.0296 & 25.56 & 0.0532 & 0.0030 \\
\hline Belize & BLZ & 25.97 & 0.2051 & 0.0117 & 25.56 & 0.0549 & 0.0030 \\
\hline Gambia & GMB & 26.22 & 0.0965 & 0.0049 & 27.88 & 0.0819 & 0.0042 \\
\hline Côte d'Ivoire & $\mathrm{CIV}$ & 26.23 & 0.1406 & 0.0075 & 26.43 & 0.0657 & 0.0034 \\
\hline Nicaragua & NIC & 26.29 & 0.1507 & 0.0081 & 25.16 & 0.0510 & 0.0029 \\
\hline Sri Lanka & LKA & 26.46 & 0.4292 & 0.0303 & 26.86 & 0.0656 & 0.0035 \\
\hline Togo & TGO & 26.48 & 0.1161 & 0.0060 & 27.36 & 0.0749 & 0.0039 \\
\hline Sierra Leone & SLE & 26.51 & 0.4489 & 0.0326 & 26.27 & 0.0565 & 0.0031 \\
\hline $\begin{array}{l}\text { St. Vincent } \\
\text { and the } \\
\text { Grenadines }\end{array}$ & VCT & 26.54 & 0.2375 & 0.0143 & 27.57 & 0.0713 & 0.0038 \\
\hline Ghana & GHA & 26.66 & 0.1322 & 0.0070 & 27.33 & 0.0743 & 0.0039 \\
\hline Nigeria & NGA & 26.72 & 0.1405 & 0.0074 & 26.89 & 0.0712 & 0.0037 \\
\hline Senegal & SEN & 26.81 & 0.0815 & 0.0041 & 28.25 & 0.0892 & 0.0046 \\
\hline Thailand & THA & 26.99 & 0.1587 & 0.0086 & 26.35 & 0.0635 & 0.0034 \\
\hline Guinea-Bissau & GNB & 27.00 & 0.1653 & 0.0090 & 27.23 & 0.0702 & 0.0037 \\
\hline Benin & BEN & 27.23 & 0.1214 & 0.0063 & 27.87 & 0.0806 & 0.0042 \\
\hline
\end{tabular}




\begin{tabular}{|c|c|c|c|c|c|c|c|}
\hline Cambodia & KHM & 27.69 & 0.1860 & 0.0104 & 27.21 & 0.0662 & 0.0036 \\
\hline Burkina Faso & BFA & 27.85 & 0.1068 & 0.0055 & 28.39 & 0.0895 & 0.0046 \\
\hline $\begin{array}{l}\text { Sudan } \\
\text { (Former) }\end{array}$ & SDN & 27.97 & 0.0829 & 0.0042 & 27.13 & 0.0826 & 0.0041 \\
\hline Djibouti & DJI & 28.06 & 0.0726 & 0.0037 & 28.06 & 0.0945 & 0.0048 \\
\hline Chad & TCD & 28.09 & 0.1029 & 0.0053 & 27.17 & 0.0839 & 0.0042 \\
\hline Mali & MLI & 28.12 & 0.1031 & 0.0053 & 28.55 & 0.0996 & 0.0051 \\
\hline Niger & NER & 28.37 & 0.0880 & 0.0045 & 27.48 & 0.0894 & 0.0045 \\
\hline Mauritania & MRT & 28.59 & 0.0769 & 0.0039 & 28.26 & 0.1001 & 0.0050 \\
\hline Myanmar & MMR & & . & & 22.99 & 0.0450 & 0.0025 \\
\hline Haiti & HTI & & . & & 24.73 & 0.0551 & 0.0029 \\
\hline Saint Lucia & LCA & & . & & 26.36 & 0.0570 & 0.0032 \\
\hline Maldives & MDV & & . & & 28.12 & 0.0704 & 0.0038 \\
\hline \multicolumn{2}{|l|}{ Poor Count } & 22.05 & 0.1124 & 0.0066 & 22.15 & 0.0511 & $\mathbf{0 . 0 0 2 7}$ \\
\hline
\end{tabular}

Note: These marginal effects are based on the stochastic production function estimates presented in Table 2

(Version 3, for both WB and BHM weather variables).

Table A7: Projected production efficiency growth impacts of temperature change based on RCP 8.5

\begin{tabular}{|c|c|c|c|c|c|c|c|}
\hline Country & $\begin{array}{l}\text { Coun } \\
\text { try } \\
\text { code }\end{array}$ & $\begin{array}{l}\text { Temperat } \\
\text { ure } \\
\text { change in } \\
2020-40 \\
\text { over } \\
2000-10\end{array}$ & $\begin{array}{l}\text { Marginal } \\
\text { effects on } \\
\text { mean of } \\
\text { TFP } \\
\text { growth } \\
(2020-40)\end{array}$ & $\begin{array}{l}\text { Marginal } \\
\text { effects on } \\
\text { variance of } \\
\text { TFP growth } \\
(2020-40)\end{array}$ & $\begin{array}{l}\text { Temperatu } \\
\text { re change } \\
\text { in } 2080- \\
2100 \text { over } \\
2000-10\end{array}$ & $\begin{array}{l}\text { Marginal } \\
\text { effects on } \\
\text { mean of } \\
\text { TFP } \\
\text { growth } \\
(2080- \\
2100)\end{array}$ & $\begin{array}{l}\text { Marginal } \\
\text { effects on } \\
\text { variance of } \\
\text { TFP } \\
\text { growth } \\
(2080- \\
2100)\end{array}$ \\
\hline Albania & ALB & 5.01 & 0.054 & 0.003 & 8.26 & 0.127 & 0.007 \\
\hline Algeria & DZA & 0.87 & 0.134 & 0.007 & 4.68 & 0.213 & 0.009 \\
\hline Angola & AGO & 2.43 & 0.151 & 0.009 & 5.68 & 0.254 & 0.011 \\
\hline Argentina & ARG & 1.84 & 0.037 & 0.002 & 4.24 & 0.057 & 0.003 \\
\hline Armenia & ARM & 2.06 & -0.007 & 0.000 & 5.72 & 0.005 & 0.000 \\
\hline Australia & AUS & 1.70 & 0.115 & -0.001 & 4.64 & 0.163 & 0.010 \\
\hline Austria & AUT & 3.66 & 0.008 & 0.000 & 6.80 & 0.031 & 0.002 \\
\hline Azerbaijan & AZE & 1.44 & 0.015 & 0.001 & 4.80 & 0.037 & 0.003 \\
\hline Bangladesh & BGD & 1.35 & 0.212 & 0.012 & 4.29 & 0.936 & 0.055 \\
\hline Belarus & BLR & 1.69 & -0.004 & 0.000 & 5.02 & -0.004 & -0.001 \\
\hline Belgium & BEL & 1.72 & 0.010 & 0.001 & 4.43 & 0.022 & 0.001 \\
\hline Belize & BLZ & 0.82 & 0.205 & 0.012 & 3.40 & 0.698 & 0.040 \\
\hline Benin & BEN & 0.20 & 0.144 & 0.008 & 3.11 & 0.242 & 0.014 \\
\hline Bhutan & BTN & 2.78 & 0.046 & 0.002 & 5.99 & 0.632 & 0.033 \\
\hline Botswana & BWA & 0.94 & 0.042 & 0.002 & 4.86 & 0.068 & 0.003 \\
\hline Brazil & BRA & 1.24 & 0.224 & 0.011 & 4.37 & 0.364 & 0.017 \\
\hline
\end{tabular}




\begin{tabular}{|c|c|c|c|c|c|c|c|}
\hline Bulgaria & BGR & 3.43 & 0.029 & 0.002 & 6.90 & 0.066 & 0.004 \\
\hline Burkina Faso & BFA & 0.79 & 0.128 & 0.007 & 4.01 & 0.267 & 0.015 \\
\hline Burundi & BDI & 1.59 & 0.064 & 0.003 & 4.62 & 0.088 & 0.004 \\
\hline Cambodia & KHM & -0.54 & 0.139 & 0.007 & 2.02 & 0.191 & 0.010 \\
\hline Cameroon & CMR & 0.18 & 0.145 & 0.008 & 2.97 & 0.091 & 0.005 \\
\hline Canada & CAN & 3.51 & -0.018 & -0.001 & 8.55 & -0.017 & -0.001 \\
\hline $\begin{array}{l}\text { Central } \\
\text { African }\end{array}$ & CAF & 0.79 & 0.127 & 0.007 & 3.79 & 0.209 & 0.012 \\
\hline Chad & $\mathrm{TCD}$ & 0.71 & 0.099 & 0.005 & 4.08 & 0.197 & 0.011 \\
\hline Chile & $\mathrm{CHL}$ & 2.72 & 0.007 & 0.000 & 5.22 & 0.023 & 0.001 \\
\hline China & $\mathrm{CHN}$ & 0.57 & 0.020 & 0.001 & 4.32 & 0.013 & 0.001 \\
\hline Colombia & $\mathrm{COL}$ & 1.00 & 0.161 & -0.008 & 3.98 & 0.223 & 0.013 \\
\hline Comoros & $\mathrm{COM}$ & 1.37 & 0.602 & 0.038 & 3.61 & 1.329 & 0.071 \\
\hline Congo & $\mathrm{COG}$ & 0.34 & 0.121 & 0.006 & 3.31 & 0.148 & 0.007 \\
\hline Costa Rica & CRI & 2.64 & 0.470 & 0.018 & 5.05 & 0.712 & 0.030 \\
\hline Croatia & HRV & 2.65 & 0.023 & 0.001 & 5.85 & 0.043 & 0.003 \\
\hline Cyprus & CYP & 1.26 & 0.078 & 0.006 & 4.12 & 0.122 & 0.010 \\
\hline $\begin{array}{l}\text { Czech } \\
\text { Republic }\end{array}$ & $\mathrm{CZE}$ & 1.34 & 0.002 & 0.000 & 4.37 & 0.013 & 0.001 \\
\hline Denmark & DNK & 1.99 & 0.005 & 0.000 & 4.42 & 0.026 & 0.002 \\
\hline Djibouti & DJI & -1.44 & 0.062 & 0.003 & 1.48 & 0.080 & 0.004 \\
\hline Ecuador & $\mathrm{ECU}$ & 2.01 & 0.115 & 0.001 & 4.73 & 0.158 & 0.015 \\
\hline Egypt & EGY & 1.75 & 0.039 & 0.002 & 5.26 & 0.053 & 0.003 \\
\hline El Salvador & SLV & 3.70 & -0.036 & -0.003 & 6.29 & 0.708 & 0.037 \\
\hline Estonia & EST & 1.03 & -0.011 & -0.001 & 4.36 & -0.016 & -0.002 \\
\hline Ethiopia & ETH & 1.12 & 0.077 & 0.004 & 3.95 & 0.102 & 0.005 \\
\hline Fiji & FJI & 2.14 & 1.412 & 0.070 & 4.10 & 1.914 & -0.029 \\
\hline Finland & FIN & 0.85 & -0.024 & -0.002 & 4.68 & -0.010 & -0.001 \\
\hline France & FRA & 1.98 & 0.016 & 0.001 & 4.85 & 0.027 & 0.002 \\
\hline Gabon & GAB & 0.67 & 0.239 & 0.013 & 3.28 & 0.497 & 0.028 \\
\hline Georgia & GEO & 2.80 & 0.005 & 0.000 & 6.22 & 0.020 & 0.001 \\
\hline Germany & DEU & 1.40 & 0.004 & 0.000 & 4.24 & 0.013 & 0.001 \\
\hline Ghana & GHA & 0.42 & 0.137 & 0.007 & 3.11 & 0.092 & 0.005 \\
\hline Greece & GRC & 3.63 & 0.049 & 0.003 & 6.87 & 0.085 & 0.004 \\
\hline Guatemala & GTM & 2.45 & 0.216 & 0.012 & 5.31 & 0.341 & 0.023 \\
\hline
\end{tabular}




\begin{tabular}{|c|c|c|c|c|c|c|c|}
\hline Guinea & GIN & 0.53 & 0.220 & 0.014 & 3.40 & 0.309 & 0.027 \\
\hline Guinea-Bissau & GNB & 1.31 & 0.372 & 0.023 & 4.05 & 1.459 & 0.096 \\
\hline Honduras & HND & 2.38 & 0.113 & 0.006 & 5.05 & 0.084 & 0.004 \\
\hline Hungary & HUN & 2.09 & 0.013 & 0.001 & 5.38 & 0.031 & 0.002 \\
\hline Iceland & ISL & 0.51 & -0.018 & -0.001 & 2.94 & -0.008 & 0.000 \\
\hline India & IND & 1.79 & 0.108 & 0.006 & 4.95 & 0.283 & 0.015 \\
\hline Indonesia & IDN & 0.98 & -0.042 & -0.007 & 3.33 & 0.904 & 0.056 \\
\hline Iraq & IRQ & 1.00 & 0.125 & 0.011 & 4.84 & 0.235 & 0.024 \\
\hline Ireland & IRL & 2.07 & 0.007 & 0.000 & 3.95 & 0.008 & 0.000 \\
\hline Israel & ISR & 1.64 & 0.094 & 0.008 & 4.80 & 0.158 & 0.014 \\
\hline Italy & ITA & 3.76 & 0.034 & 0.002 & 6.75 & 0.056 & 0.004 \\
\hline Jamaica & JAM & 2.10 & 0.313 & 0.019 & 4.26 & 0.436 & 0.035 \\
\hline Japan & JPN & 3.27 & 0.025 & 0.001 & 6.37 & 0.042 & 0.001 \\
\hline Jordan & JOR & 2.26 & 0.090 & 0.008 & 5.85 & 0.150 & 0.013 \\
\hline Kazakhstan & $\mathrm{KAZ}$ & 3.81 & -0.002 & 0.000 & 7.56 & 0.014 & 0.001 \\
\hline Kenya & KEN & 0.09 & 0.099 & 0.005 & 2.77 & 0.154 & 0.008 \\
\hline Kuwait & KWT & 0.90 & 0.237 & 0.025 & 4.75 & 0.472 & 0.061 \\
\hline Kyrgyzstan & KGZ & 1.45 & -0.022 & -0.002 & 5.45 & -0.014 & -0.001 \\
\hline Latvia & LVA & 1.44 & -0.005 & 0.000 & 4.63 & 0.002 & 0.000 \\
\hline Lebanon & LBN & 4.62 & 0.076 & 0.005 & 7.64 & 0.110 & 0.007 \\
\hline Lesotho & LSO & 2.10 & 0.015 & 0.001 & 5.53 & 0.029 & 0.002 \\
\hline Liberia & LBR & 0.99 & 0.579 & 0.048 & 3.48 & 0.745 & 0.138 \\
\hline Lithuania & LTU & 1.65 & -0.004 & 0.000 & 4.80 & -0.006 & -0.001 \\
\hline Luxembourg & LUX & 1.75 & 0.008 & 0.000 & 4.52 & 0.023 & 0.001 \\
\hline Madagascar & MDG & 1.44 & 0.256 & 0.013 & 4.00 & 0.593 & 0.030 \\
\hline Malawi & MWI & 1.13 & 0.068 & 0.003 & 4.38 & 0.097 & 0.005 \\
\hline Malaysia & MYS & 0.77 & 0.352 & 0.016 & 3.22 & 0.596 & 0.042 \\
\hline Mali & MLI & 0.58 & 0.116 & 0.006 & 4.25 & 0.265 & 0.014 \\
\hline Mauritania & MRT & 0.55 & 0.079 & 0.004 & 4.27 & 0.166 & 0.009 \\
\hline Mauritius & MUS & 1.31 & 0.143 & 0.008 & 3.40 & 0.463 & 0.026 \\
\hline Mexico & MEX & 0.33 & 0.087 & 0.005 & 3.34 & 0.133 & 0.005 \\
\hline Mongolia & MNG & 2.14 & -0.036 & -0.003 & 6.14 & -0.023 & -0.002 \\
\hline Morocco & MAR & 2.62 & 0.044 & 0.002 & 6.30 & 0.104 & 0.005 \\
\hline Mozambique & $\mathrm{MOZ}$ & 0.76 & 0.077 & 0.004 & 3.74 & 0.021 & 0.001 \\
\hline
\end{tabular}




\begin{tabular}{|c|c|c|c|c|c|c|c|}
\hline Namibia & NAM & 2.48 & 0.127 & 0.011 & 5.78 & 0.218 & 0.026 \\
\hline Nepal & NPL & 6.99 & 0.062 & 0.003 & 10.41 & 0.044 & 0.002 \\
\hline Netherlands & NLD & 1.86 & 0.010 & 0.001 & 4.40 & 0.022 & 0.001 \\
\hline New Zealand & NZL & 3.07 & 0.019 & 0.001 & 5.35 & 0.029 & 0.002 \\
\hline Nicaragua & NIC & 1.87 & 0.132 & 0.007 & 4.40 & 0.663 & 0.036 \\
\hline Niger & NER & 0.22 & 0.084 & 0.004 & 3.75 & 0.148 & 0.008 \\
\hline Nigeria & NGA & 0.41 & 0.149 & 0.008 & 3.32 & 0.017 & 0.000 \\
\hline Norway & NOR & 1.65 & -0.016 & -0.001 & 4.79 & -0.006 & 0.000 \\
\hline Oman & OMN & 2.54 & 0.330 & 0.035 & 5.66 & 0.563 & 0.056 \\
\hline Pakistan & PAK & 1.48 & 0.041 & 0.002 & 5.21 & 0.048 & 0.002 \\
\hline Panama & PAN & 1.72 & 0.523 & 0.027 & 4.14 & 0.990 & 0.061 \\
\hline Paraguay & PRY & 2.45 & 0.204 & 0.010 & 5.56 & 0.327 & 0.013 \\
\hline Peru & PER & 1.81 & 0.086 & 0.005 & 4.97 & 0.127 & 0.008 \\
\hline Philippines & PHL & 1.78 & -0.168 & -0.024 & 4.08 & 1.407 & 0.096 \\
\hline Poland & POL & 2.17 & 0.004 & 0.000 & 5.21 & 0.021 & 0.001 \\
\hline Portugal & PRT & 1.81 & 0.042 & 0.002 & 4.83 & 0.072 & 0.001 \\
\hline Qatar & QAT & 0.93 & 0.338 & 0.040 & 4.53 & 0.642 & 0.085 \\
\hline Rwanda & RWA & 1.56 & 0.063 & 0.003 & 4.54 & 0.084 & 0.004 \\
\hline Saudi Arabia & SAU & 0.98 & 0.215 & 0.022 & 4.72 & 0.418 & 0.051 \\
\hline Senegal & SEN & 1.32 & 0.165 & 0.009 & 4.29 & 0.373 & 0.020 \\
\hline Serbia & SRB & 1.98 & 0.008 & 0.001 & 5.41 & -0.004 & 0.001 \\
\hline Sierra Leone & SLE & 0.05 & 0.401 & 0.026 & 2.68 & 3.232 & 0.381 \\
\hline Slovakia & SVK & 2.98 & 0.010 & 0.001 & 6.19 & 0.032 & 0.002 \\
\hline Slovenia & SVN & 3.28 & 0.025 & 0.001 & 6.47 & 0.054 & 0.003 \\
\hline South Africa & ZAF & 0.81 & 0.058 & 0.004 & 4.08 & 0.099 & 0.007 \\
\hline Spain & ESP & 2.73 & 0.036 & 0.002 & 5.89 & 0.069 & 0.004 \\
\hline Sri Lanka & LKA & 0.85 & 0.470 & 0.033 & 3.18 & 1.594 & 0.127 \\
\hline Suriname & SUR & 1.64 & 0.407 & 0.025 & 4.35 & 0.744 & 0.066 \\
\hline Swaziland & SWZ & -1.50 & 0.041 & 0.002 & 1.46 & 0.034 & 0.002 \\
\hline Sweden & SWE & 2.30 & -0.018 & -0.001 & 5.53 & -0.008 & -0.001 \\
\hline Switzerland & $\mathrm{CHE}$ & 3.34 & 0.006 & 0.000 & 6.45 & 0.014 & 0.001 \\
\hline Tajikistan & TJK & -0.21 & 0.051 & 0.003 & 4.03 & 0.008 & 0.000 \\
\hline Thailand & THA & -0.04 & 0.156 & 0.008 & 2.60 & 0.273 & 0.016 \\
\hline Togo & TGO & 0.56 & 0.140 & 0.007 & 3.36 & 0.232 & 0.014 \\
\hline
\end{tabular}




\begin{tabular}{|c|c|c|c|c|c|c|c|}
\hline Tunisia & TUN & 1.25 & 0.040 & 0.002 & 4.61 & 0.086 & 0.004 \\
\hline Turkey & TUR & 3.35 & 0.026 & 0.002 & 6.84 & 0.053 & 0.003 \\
\hline Turkmenistan & TKM & 1.85 & 0.049 & 0.004 & 5.32 & 0.089 & 0.008 \\
\hline Uganda & UGA & 0.40 & 0.076 & 0.004 & 3.22 & 0.064 & 0.003 \\
\hline Ukraine & UKR & 2.91 & 0.011 & 0.001 & 6.22 & 0.030 & 0.002 \\
\hline $\begin{array}{l}\text { United } \\
\text { Kingdom }\end{array}$ & GBR & 2.00 & 0.006 & 0.000 & 4.12 & 0.011 & 0.001 \\
\hline United States & USA & 2.25 & 0.003 & 0.000 & 5.97 & 0.018 & 0.001 \\
\hline Uruguay & URY & 2.11 & 0.070 & 0.004 & 4.42 & 0.100 & 0.006 \\
\hline Uzbekistan & UZB & 2.86 & 0.014 & 0.001 & 6.41 & 0.052 & 0.003 \\
\hline Yemen & YEM & 2.55 & 0.038 & 0.002 & 5.56 & 0.233 & 0.012 \\
\hline Zambia & ZMB & 1.55 & 0.063 & 0.003 & 5.03 & 0.074 & 0.004 \\
\hline Zimbabwe & ZWE & 1.36 & 0.051 & 0.003 & 4.88 & 0.107 & 0.005 \\
\hline Average & & 1.70 & 0.110 & 0.006 & 4.76 & 0.258 & 0.018 \\
\hline $\begin{array}{c}\text { Standard } \\
\text { Deviation }\end{array}$ & & 1.19 & 0.174 & 0.011 & 1.35 & 0.437 & 0.041 \\
\hline Maximum & & 6.99 & 1.412 & 0.070 & 10.41 & 3.232 & 0.381 \\
\hline Minimum & & -1.50 & -0.168 & -0.024 & 1.46 & -0.023 & -0.029 \\
\hline
\end{tabular}


Figure A1: Regional distribution of marginal effects of temperature (WB) on production inefficiency growth

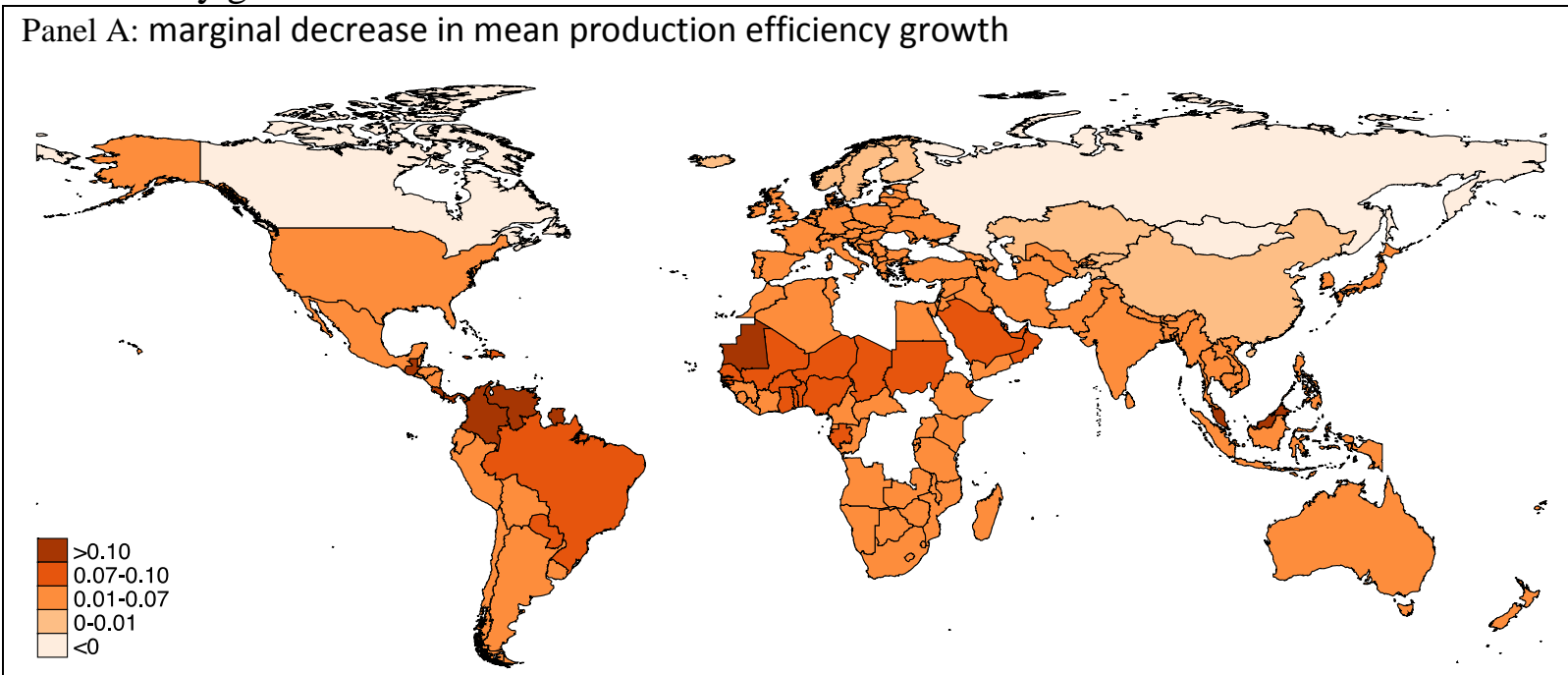

Panel B: marginal increase in variance production efficiency growth
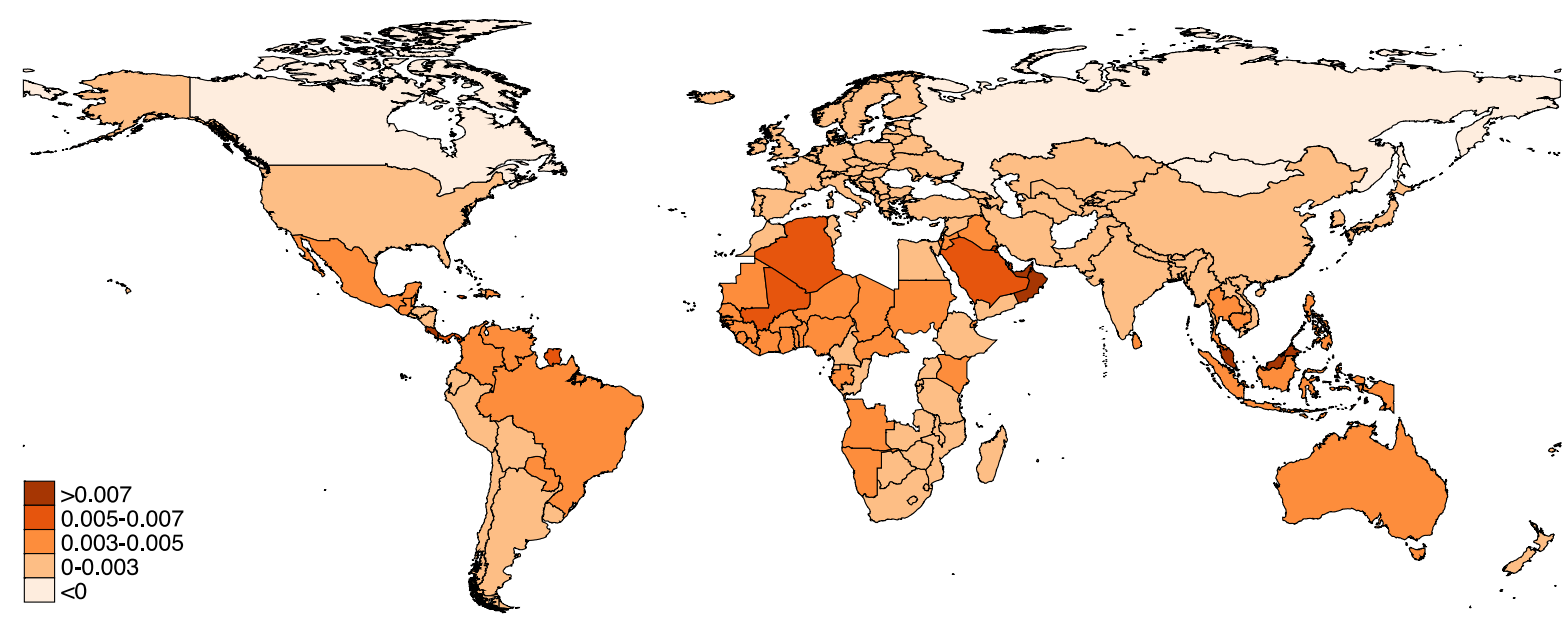

Note: Hotter than average temperature is not only detrimental to production efficiency growth but also makes the growth less stable than otherwise and these effects are larger in very hot countries with average annual temperature greater than $25{ }^{\circ} \mathrm{C}$. Countries such as Mongolia benefit from any further temperature increase, but hot countries like Brunei Darussalam have to face the hardest detrimental effects. 
Figure 2A: Relationship between the marginal effects of temperature, its level and per capita income

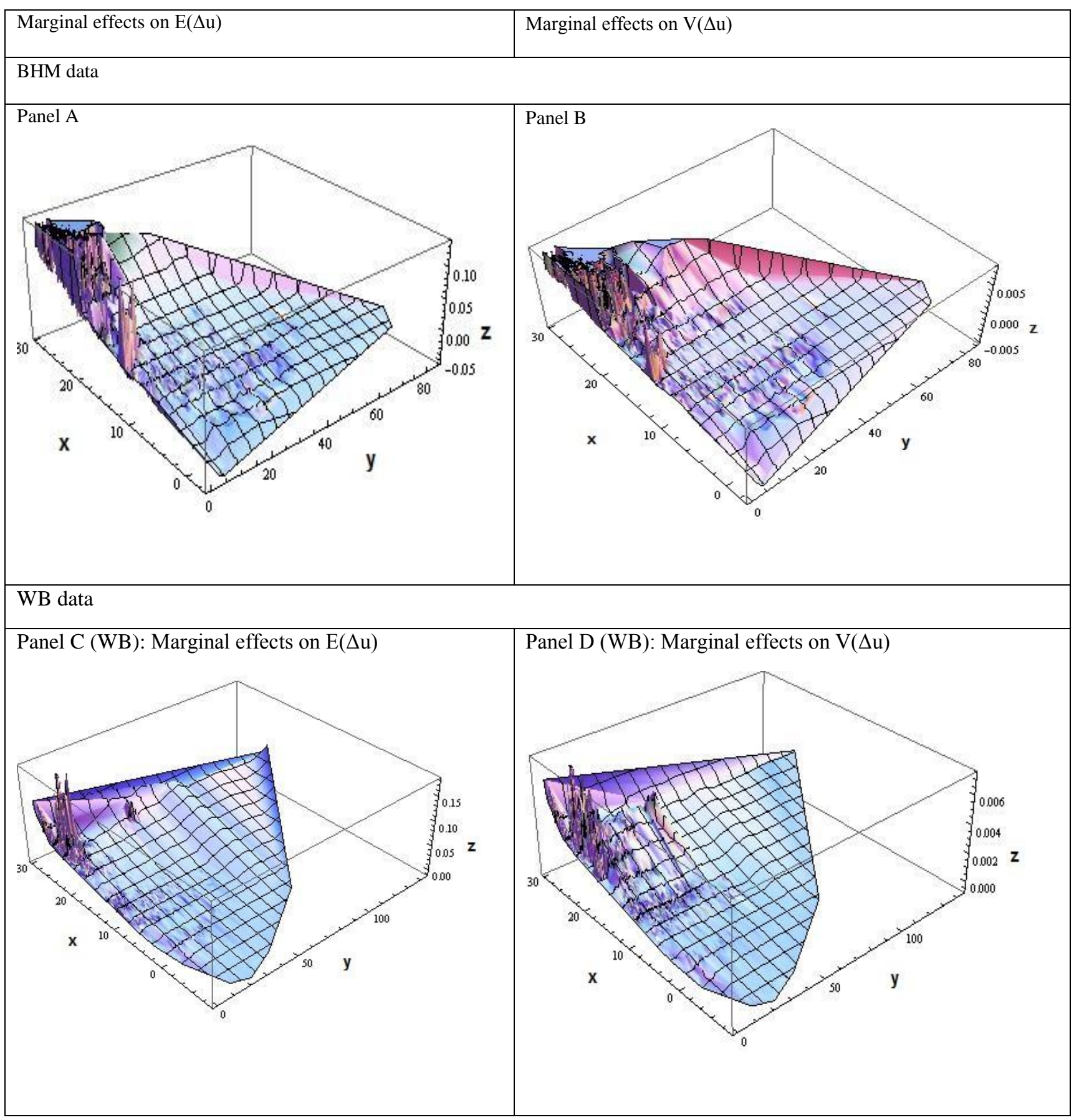

Note: Notes: $\mathrm{x}$-axis measures temperature in ${ }^{\circ} \mathrm{C}$; $\mathrm{y}$-axis measures per capita income in thousand 2011US\$ in terms of PPP; and z-axis measures the marginal effect of temperature change on mean inefficiency growth. The effects are higher in high temperature and low income countries, i.e., higher income moderates detrimental temperature effects in countries which observe on average less than $25^{\circ} \mathrm{C}$ temperature. ${ }^{22}$

${ }^{22}$ In the formulation of these figures following countries information is not included: Countries with high per capita income and temperature $(\mathrm{BHM})>25$ : United Arab Emirates, Bahamas, Brunei Darussalam, Dominican Republic, Gabon, Equatorial Guinea, Kuwait, Malaysia, Oman, Panama, Qatar, Saudi Arabia, Suriname, Thailand, Trinidad and Tobago, Bolivarian Republic of Venezuela. Countries with high per capita income and temperature (WB) > 25: Aruba, Anguilla, United Arab Emirates, Bahrain, Bahamas, Brazil, Barbados, Brunei Darussalam, Costa Rica, Cayman Islands, Gabon, Equatorial Guinea, Kuwait, Maldives, Malaysia, Oman, Panama, Qatar, Saudi Arabia, Singapore, Suriname, Seychelles, Thailand, 
Figure A3: Projected Marginal Effects based on projected temperature of 2020-2040

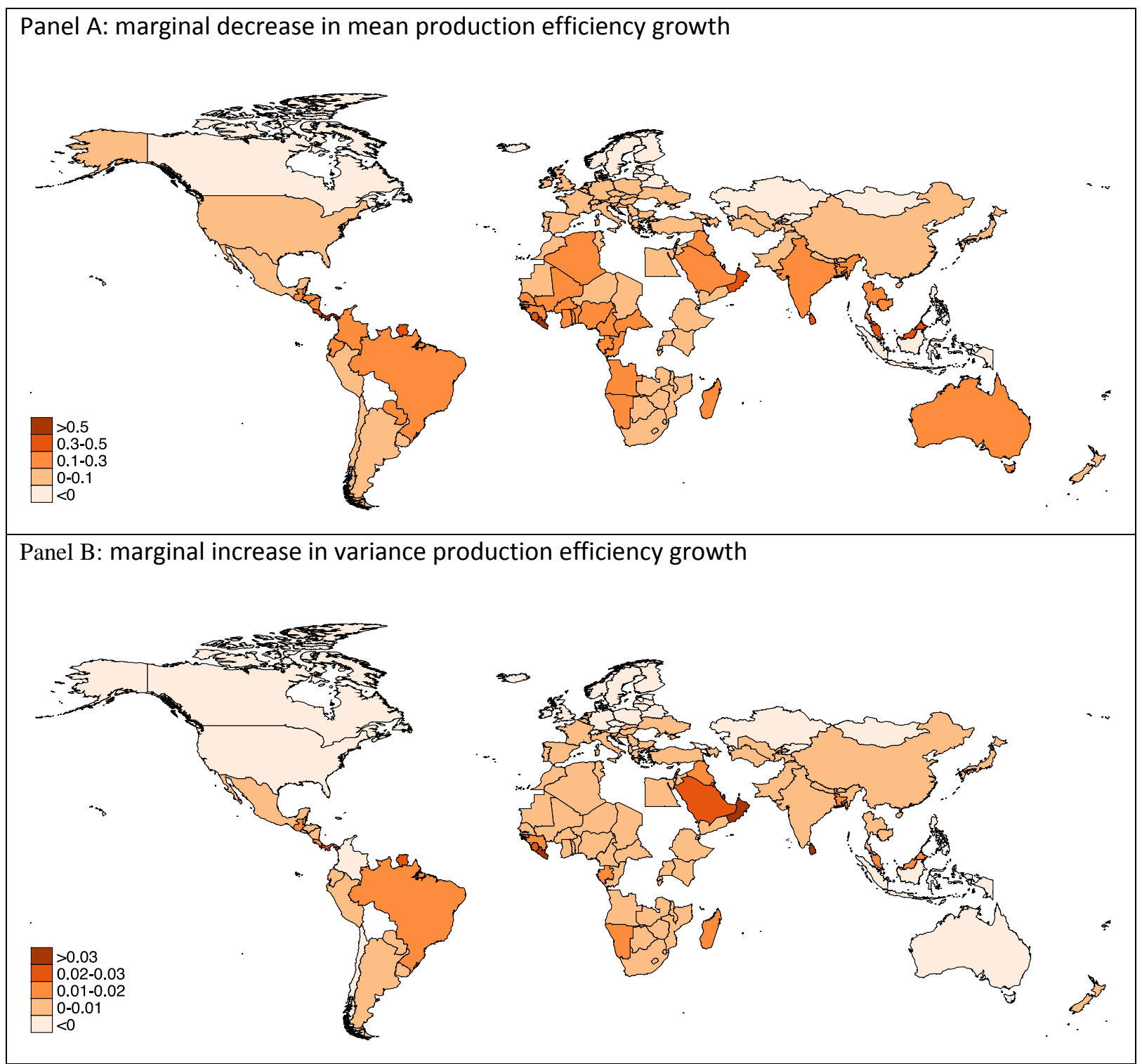

Note: Poor countries are more vulnerable than rich countries though they face similar or lower temperature increase since marginal effects are a function of base level temperature and economic development. The marginal effects are more pronounced in the countries of South Asia, Sub-Saharan region, OPEC and Latin America.

Trinidad and Tobago, Bolivarian Republic of Venezuela. In very hot climate zone, the marginal effects of temperature are identical across countries irrespective of their level of development, therefore excluding these rich countries in the Figure makes the three-way relationship sharper. 